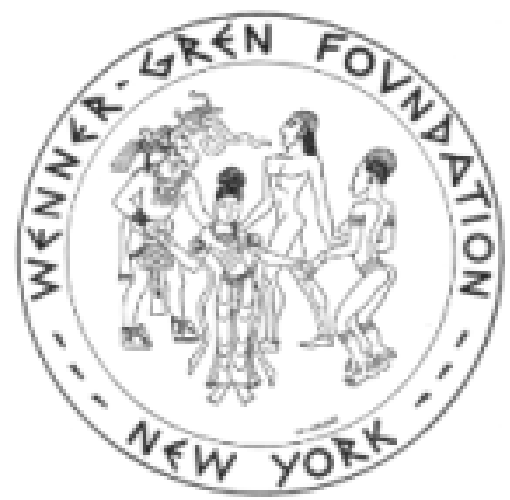

Political Economy in Prehistory: A Marxist Approach to Pacific Sequences Author(s): Timothy Earle and Matthew Spriggs

Source: Current Anthropology, Vol. 56, No. 4 (August 2015), pp. 515-544

Published by: The University of Chicago Press on behalf of Wenner-Gren Foundation for

Anthropological Research

Stable URL: http://www.jstor.org/stable/10.1086/682284

Accessed: 08/09/2015 12:58

Your use of the JSTOR archive indicates your acceptance of the Terms \& Conditions of Use, available at http://www.jstor.org/page/info/about/policies/terms.jsp

JSTOR is a not-for-profit service that helps scholars, researchers, and students discover, use, and build upon a wide range of content in a trusted digital archive. We use information technology and tools to increase productivity and facilitate new forms of scholarship. For more information about JSTOR, please contact support@ jstor.org. 


\title{
Political Economy in Prehistory
}

\author{
A Marxist Approach to Pacific Sequences
}

\author{
by Timothy Earle and Matthew Spriggs
}

\begin{abstract}
Development of strong leaders and social stratification in prehistory is suitable for a political economy approach to the longue durée. Our goal is to encourage archaeologists to formulate prehistoric research that draws on historical materialism, the Marxist reasoning for understanding political economy. Three prehistoric cases from the Pacific (Lapita, Vanuatu, and Hawai ii) help us evaluate the steps required to do this. Most importantly, we identify economic bottlenecks (constriction points) based on property rights for land or on production and trade of prestige goods. Resources can be mobilized by emergent elites at such bottlenecks to support strategies that enmesh land managers, captains, warriors, and priests to centralize power. A political economy approach in prehistory can help explain striking parallels observed for independent sequences as well as conjunctures and divergences in specific world culture areas.
\end{abstract}

In prehistory, there was a time before strong leaders and social stratification. Whether strong leaders emerged depended on their success or failure controlling the political economy, using warrior might, and fashioning a validating cultural ethos (Earle 1997; Mann 1986). Any theory of social inequality must consider how such power was controlled and resisted. Although political economy approaches to social inequality and power have primarily concerned modern worlds of markets and capitalism, these same approaches can be generalized for longer-term comparative studies of archaeological sequences.

Our method continues a long tradition of political economy studies in ancient human history. Relying on the ethnographic accounts of Lewis Henry Morgan (1877) and others, Marx (1967 [1867]) and Engels (1972 [1884]) saw opportunities to explain long-term evolutionary trends (see Spriggs $1997 c$ for sources). Drawing on the rich ethnographies of the twentieth century, US anthropologists (Fried 1967; Sahlins 1958; Service 1962; Steward 1955; White 1958; and, recently, Bowles, Smith, and Mulder 2010) formulated popular evolutionary models; however, because they looked only at contemporary groups (without actual historical sequences), their work became heavily criticized as conjectural history. The leading British social anthropologist of the time said bluntly,

Timothy Earle is Professor Emeritus in the Department of Anthropology of Northwestern University (1810 Hinman Avenue, Evanston, Illinois 60208, USA [tke299@northwestern.edu]). Matthew Spriggs is Professor of Archaeology in the School of Archaeology and Anthropology in the College of Arts and Social Sciences of the Australian National University (AD Hope Building, Canberra, Australian Capital Territory 0200, Australia [matthew.spriggs@anu.edu.au]). This paper was submitted 16 XII 13 , accepted 11 X 14, and electronically published 20 VII 15.
"In the primitive societies that are studied by social anthropologists there are no historical records" (Radcliffe-Brown 1952:3). Archaeology, however, can reveal that material record, and we believe that a political economy approach provides the means to look at how specific archaeological histories have resulted in striking parallels, conjunctures, and divergences.

V. Gordon Childe (1942) was inspirational in efforts to integrate archaeological evidence with a political economy (Marxist) approach to understand how human societies developed (Trigger 1980). At the end of his career, Childe (1958) evaluated his life's work in archaeology, sensing that, although his approach was correct, archaeology lacked the means to study political economy effectively. At the same time, however, US archaeologists were developing new methods to do just what Childe desired. Steward's focus on settlement patterns and White's on energy inspired a generation of archaeologists elaborating materialist understandings of prehistory (Willey and Sabloff 1974). A lively debate emerged among US archaeologists as to the efficacy of ecological, political, and structural ways to understand change (Adams 1966; Blanton et al. 1981; Earle 1978; Flannery 1972; Gilman 1981, 1989; Hayden 1983). Although much of the US processual tradition is generally grounded in Marxism, US scholars were reluctant to identify themselves explicitly as Marxist, perhaps because of the lingering sense that it was "un-American."

Among British scholars, the encounter with Marxism during the 1970s was different (McGuire, O'Donovan, and Wurst 2005). It came into British archaeology via French Marxist cultural anthropology, mediated by Jonathan Friedman and Jack Goody. ${ }^{1}$ Friedman's (1974) paper “Marxism, Structural-

1. Jack Goody ran the first UK undergraduate seminar course in Marxist anthropology during the mid-1970s at the University of 
ism, and Vulgar Materialism" provided a rallying cry for young European archaeologists. Friedman and Rowlands (1978) applied a structural Marxist analysis to understand prehistoric political economy in Europe and Asia, while Spriggs (1984) edited a book on Marxist archaeology that also adopted a structural perspective. But Friedman's criticism of "vulgar materialism" felt dismissive to US processualists, who often withdrew further from engagements with Marxism. Historical materialism fragmented into feuding camps, allowing Ian Hodder (1982) to create without coherent response an antimaterialist reasoning to archaeology drawing on postmodernist theory. The limitations of his postprocessualism are now recognized, and creative responses call for expanded and dynamic materialism (Brumfiel 1992) and "processualism plus" (Hegmon 2003). We believe that a political economy (Marxist) approach should be foundational to the renewed processualism.

Archaeologists should emphasize what we do beststudying actual sequences in the longue durée. Dedicated to building a science-based understanding of human history within a broadly Marxist paradigm, we examine historically interrelated sequences from the Pacific to illustrate the potential strengths of a new synthesis. We describe how control over property was the likely foundation for the emergence of stratified Polynesian societies and, under different conditions, how dominant control was effectively resisted to create more decentralized structures in much, but not all, of Melanesia.

\section{Generalizing a Political Economy Approach}

Political power involves an ability to maneuver a group to act together in the leader's interest, which often conflicts with the interests of others. We emphasize how problematic political power really must be. In some senses power is distributive, meaning that it inherently spreads out through societies. Individuals and groups attempt to access existing sources of power to further their interests. "The history of all hitherto existing society is the history of class struggles" (Marx and Engels 2012 [1848]). If we generalize the analysis of class conflict, social evolution can be seen as a power struggle between social segments (kin groups, communities, ethnic groups, political factions, and regional polities) in shifting, decentralized fields of power (see Brumfiel 1992; Saitta 2005). How, then, does the concentration of power occur? We emphasize that elemental powers derived from economy, warrior might, and religious ideology (Earle 1997; Mann 1986). Each of these sources has unique properties and social consequences, and together they derive from control of the means of production, of coercion, and of symbolic legitimation. None of these was dominant, because would-be leaders used them opportunistically. Political power was always a work in progress, as likely to dissolve as to be augmented. Chiefs were

Cambridge. Its influence on a generation of young scholars in both anthropology and archaeology has been underappreciated. crafty political operatives, exemplified by Machiavelli's Prince, seizing on whatever means available to gain and retain power. And power strategies involved an intertwining of the different power sources, each used to reinforce the others. The political economy was, however, the fount for surplus used to expand all powers.

The political economy in the past involved an economic structuring to channel resource flows (food, labor, wealth, and weapons) to finance power strategies. Political economy approaches may sometimes verge on all-encompassing social philosophies (Roseberry 1989), but we prefer to return to Marxist roots, emphasizing the ways that economic flows structure political relationships and general well-being.

During the Industrial Revolution, a political economy approach emerged to understand how economies satisfied people's needs and desires. Adam Smith (1778), measuring the wealth of nations through consumption, argued that increasing specialization and free markets lowered commodity prices, thus increasing well-being for all. He wanted to break the power of sovereigns to offer monopolies (bottlenecks) to insiders. Smith's ideas were radical-to establish unregulated markets to free people from the monarchy and landed gentry. Ricardo (1817 [1811]) conceptualized emerging conditions of land, labor, and capital that created a class structure, where landowners received rents, capitalists received profits, and laborers received wages. He believed, however, that smallscale production and trade, typical of the time, allowed open entry to profitable enterprises such that competition would keep profits within reason. But neither Smith nor Ricardo could imagine the ensuing changes in the Industrial Revolution, when steamships, trains, and large factories created monopolistic control over capital. The world of robber barons, exercising monopolistic powers, was what Marx (1967 [1867]) saw and challenged. Constrictions in capital flows created seemingly limitless opportunities to concentrate wealth. For example, Vanderbilt concentrated 5\% of all US wealth within his grasp (Stiles 2009:4). Rule by the sovereign, so overtly rejected by Adam Smith, was under threat of replacement by a ruling capitalist class. Although partly offset by antimonopolistic laws, crony capitalism still infuses the political process, and extraordinary income inequalities persist. Modern political economy analyses continue to study the ways that property rights channel flows of materials, commodities, and labor to structure social inequalities and political power. ${ }^{2}$ As the twenty-first century progresses, income inequalities nationally and internationally are reaching deplorable levels.

We aim to investigate these themes in the time before modern history, when local agricultural production and trade in wealth goods dominated political economies. In Karl Marx: Pre-Capitalist Economic Formations, Hobsbawm (1965) intro-

2. The literature on political economy is vast, subdivided along disciplinary lines that cannot be reviewed here. The reader is referred to such relevant journals as the Journal of Political Economy and the Journal of Australian Political Economy. 
duces Marx's writings on premodern economies to highlight Marx's attempts to investigate the full sweep of human history. The quality of evidence available to Marx was, however, totally inadequate, and now we can get the historical details right. Systematic and rich data allow archaeologists to address such important theoretical questions (Smith et al. 2012). Some will find our tactics unacceptable, because they are not true to Marx's original analyses. Although foundational to our thinking, we seek to extend his thinking to the very different conditions of prehistory. A political economy approach can help to identify alternative patterns of development that archaeologists now are recording (Flannery and Marcus 2012; Spriggs 2013; Trigger 1998, 2003).

\section{Political Economy in Prehistory}

"Just as Darwin discovered the law of development of organic nature, so Marx discovered the law of development of human history" (Engels 1883:1). Our analysis of the political economy in prehistory requires the identification of conditions responsible for emergent social stratification and political control. Marx believed that change must be understood in terms of historical materialism, the specific economic conditions that allowed the domination of one group (class) over another. Historical materialism never entails a simple reduction to economic factors, because economic relations are structured socially and politically. The realities of domination depend on the modes of production, including technology, property, and social relations (Hobsbawm 1965). To simplify Marx's analysis to one that can be applied across history, we stress that the development of central power and social stratification was grounded in conditions that created bottlenecks, allowing hierarchical property relations to emerge (cf. McGuire 2008b).

Bottlenecks are constriction points in commodity chains that offer an aspiring leader the opportunity to limit access, thus creating ownership over resources, technologies, or knowledge. Ownership facilitates the extraction of surpluses as corvée labor, rent, or other payments that fund power strategies. Bottlenecks emerge as unintended consequences of environmental conditions (such as highly productive land) or as intended consequences of strategic actions (such as construction of fortifications overlooking trade routes). The emergent potential to control strategic points is, as we see it, the selective mechanism for change. A political economy approach by archaeologists should work to reveal bottlenecking dynamics across the full spectrum of societies, from small scale and egalitarian to large scale, autocratic, and highly stratified (McGuire 2008b; Saitta 2005), with alternative pathways to complexity (Blanton and Fargher 2008; Blanton et al. 1996; Ehrenreich, Crumley, and Levy 1995; Gilman 1995; Kristiansen 2007; McIntosh 1999). We reject any unilinear sequence of development but look for shared processes that influence long-term change along alternative pathways.

Although bottlenecks constrict commodity flows, that constriction is relative, never absolute. Take, for example, an ir- rigation system over which a chief asserts ownership. Commoners receive plots of irrigated land in return for corvée labor and other obligations. But commoners are not powerless, because their labor alone makes the irrigation system productive, and alternatives (with costs determined by specific historical conditions) always exist. If corvée obligations are too onerous, farmers can move to work for another, less exploitative chief or can move outside the sphere of chiefs to construct independent farms. The relative constriction of the chief's irrigation system is based on the cost to farmers to move away. Another example of a bottleneck is crafting symbolic items, such as highly decorated pottery, that can be controlled by chiefs patronizing gifted artisans. But if the ceramic technology is not sufficiently elaborate and esoteric to restrict knowledge and skill to a very few artisans, others can produce copies that serve effectively, and chiefly control over the object is reduced. For the prehistoric chief (and archaeologist), the question must always be the degree to which control can be exercised-a balance between chiefly strategies and competition versus commoner evasion and subversion.

To analyze prehistoric sequences from a political economy perspective, archaeologists should start with concrete elements of the general economy (see Sayer 1987). Objects produced, traded, and used in prehistoric economies represent a wide spectrum of things with subsistence, social, and symbolic values (Bell 2004). Each object involves a commodity chain through which it was made, exchanged, and used. To construct a model of the political economy, we identify those things that mattered most in particular societies and then examine their commodity chains for potential bottlenecks that would allow surplus extraction. First, we examine the subsistence sector of traditional economies, geared to providing food and objects of everyday life (Earle 2002). Then we examine production and distribution of bodily decoration, weaponry, and the like used to define identity, group membership, social networks, status, and political ideologies (Friedman and Rowlands 1978; Hayden 1983).

Bottlenecks offer would-be chiefs the possibility to mobilize surplus of staples or wealth, but often no effective control points existed, and mobilization of surpluses was problematic. We envision that a political economy method must consider not only the centralizing potential of bottlenecks but also the countervening opportunities for commoners to act free from elite control. The important point is that political economies effective for extracting surplus could be constructed only in certain situations (D'Altroy and Earle 1985), and in traditional societies independent commoner actions characterized most situations (Robin 2013).

Political economies can be heuristically characterized as based on staple and wealth (prestige-goods) finance depending on the objects mobilized from particular bottlenecks (D'Altroy and Earle 1985). Chiefs were political actors who rose and fell as control points for key objects changed.

For staples, commodity chains were short; a farming family typically produced food for personal use and for exchange 
with neighbors. A potential bottleneck must have involved access to agricultural land and other resources over which chiefs could assert ownership. As terracing, drainage, and irrigation improved agricultural land, elites could assert ownership to extract rents on these highly productive and limited resources. Warrior might and religious ideology guaranteed chiefly ownership often associated with permanent facilities (terracing and irrigation), and monumental construction defined patterns of corporate ownership (Blanton et al. 1996).

For prestige goods, bottlenecks were more varied, with many possible points of control, such as along the extended commodity chains of metal crafting and trade in Bronze Age Eurasia (Earle 2013; Friedman and Rowlands 1978). Points of control included ownership of mines or boats, restricted trade routes along major rivers, and work by highly skilled artisans. Warriors interdicted and/or protected movements of wealth and prestige.

Compatible with the reasoning proposed here, worldsystems analysis (Frank 1993; Friedman and Friedman 2008; Wallerstein 1974) aims at the macroeffects of international trade and exchange flows. Our focus, rather, is on the smaller scale of individual societies, where conditions (often implicated in larger-scale processes) created opportunities for control at the local level. World systems did not expand to remote Pacific islands until later than the periods being considered here.

\section{A Political Economy Approach to Pacific Prehistory}

Three archaeological sequences in the Pacific illustrate how a political economy approach helps to understand the parallel and divergent trajectories of long-term change. With at least an implicit political economy reasoning, major scholars have investigated evolutionary variation in the Pacific (Dow and Reed 2013; Goldman 1970; Hommon 2013; Kirch 1984, 2010; Sahlins 1958; Younger 2012). With the exception of Kirch, however, these scholars have made little use of archaeology. We ask fundamental questions of the archaeological record: How and when did chiefs come to power in Melanesia and Polynesia? What do these cases reveal about the different pathways to power through the political economy?

When Lapita (and, later, Lapita-derived) populations colonized the Pacific Islands both close to and distant from continental areas, would-be leaders confronted varying opportunities to establish political economies, some creating complex chiefdoms or even states. Alternative, more open political systems were also established. Although each colonizing population in the Pacific evidently arrived with some structure of social inequalities, the initial inequity was apparently suspended, as open possibilities existed in newly discovered islands. To lesser or greater degrees, the societies of Oceania subsequently developed (or redeveloped) structures of power independently and quite differently, one island group to the next, based on specific conditions within their political economies.
We illustrate how to build models of these emergent political economies with three prehistoric cases (figs. 1,2). The Lapita phenomenon represents the political dynamics of colonization; subsequently, the Vanuatu case illustrates the alternative pathways of development across a single island group in Melanesia; and the Hawaiian case represents the singularity for the emergence of state-like polities in Polynesia. The evidence is presently inadequate to test our models fully; rather, our comparative method should be seen as formulating productive avenues for research that we hope will encourage ongoing collection and analysis of archaeological data.

\section{Lapita}

Excluding some earlier-settled islands in Micronesia (Carson 2013), Lapita consisted of the founding population from which all Austronesian Pacific societies arose. Lapita culture appeared abruptly sometime around 3300 BP in the Bismarck archipelago, signaling significant migration and rapid spread of many Lapita social groups across the Solomon Islands and colonizing Vanuatu, New Caledonia, Fiji, Tonga, and Samoa (fig. 2). The pattern of colonization was expansionistic and purposeful, relying on effective navigational knowledge and technology (Irwin 1992). The goals were probably to search out undiscovered islands that could offer easy subsistence, exchangeable products, and a basis for leaders to establish themselves independently (Hayden 1983). Initial settlements were widely scattered, suggesting that small populations were located along the beaches on little and large islands. As Lapita groups moved into the Pacific, their culture and social forms were changing. Although Lapita political organization is poorly understood, Green (1994, 2002) and Kirch (1997) argue for simple chiefdoms or similar midsize polities.

Lapita was defined by a distinctive decorated pottery and similar artifact inventories, including decorative shell objects, small stone adzes and obsidian, and small coastal settlements. The Lapita subsistence economy included hunting (rapidly depleting land fauna), reef fishing, and small-scale, diverse farming. To understand the political economy of Lapita, we looked for potential constriction points in staple and wealth production and exchange. We believe that the mobilization of staples was unlikely to finance power relationships among Lapita groups, because wild lands and reefs and shifting fields for extensive agriculture were probably open to all. Staple finance and its corvée labor characteristically involved monumental architecture (Blanton et al. 1996), and no such constructions are found in Lapita settlements. In addition, except for display ceramics, evidence of large-scale feasting is lacking, suggesting that local leaders could not easily mobilize staples for competitive displays. Probably no property bottlenecks existed for Lapita, and individuals acted with few constraints in subsistence procurement.

Friedman (1981, 1982; Kirch 1991) argued, however, that wealth moved between Lapita social groups through exchanges 


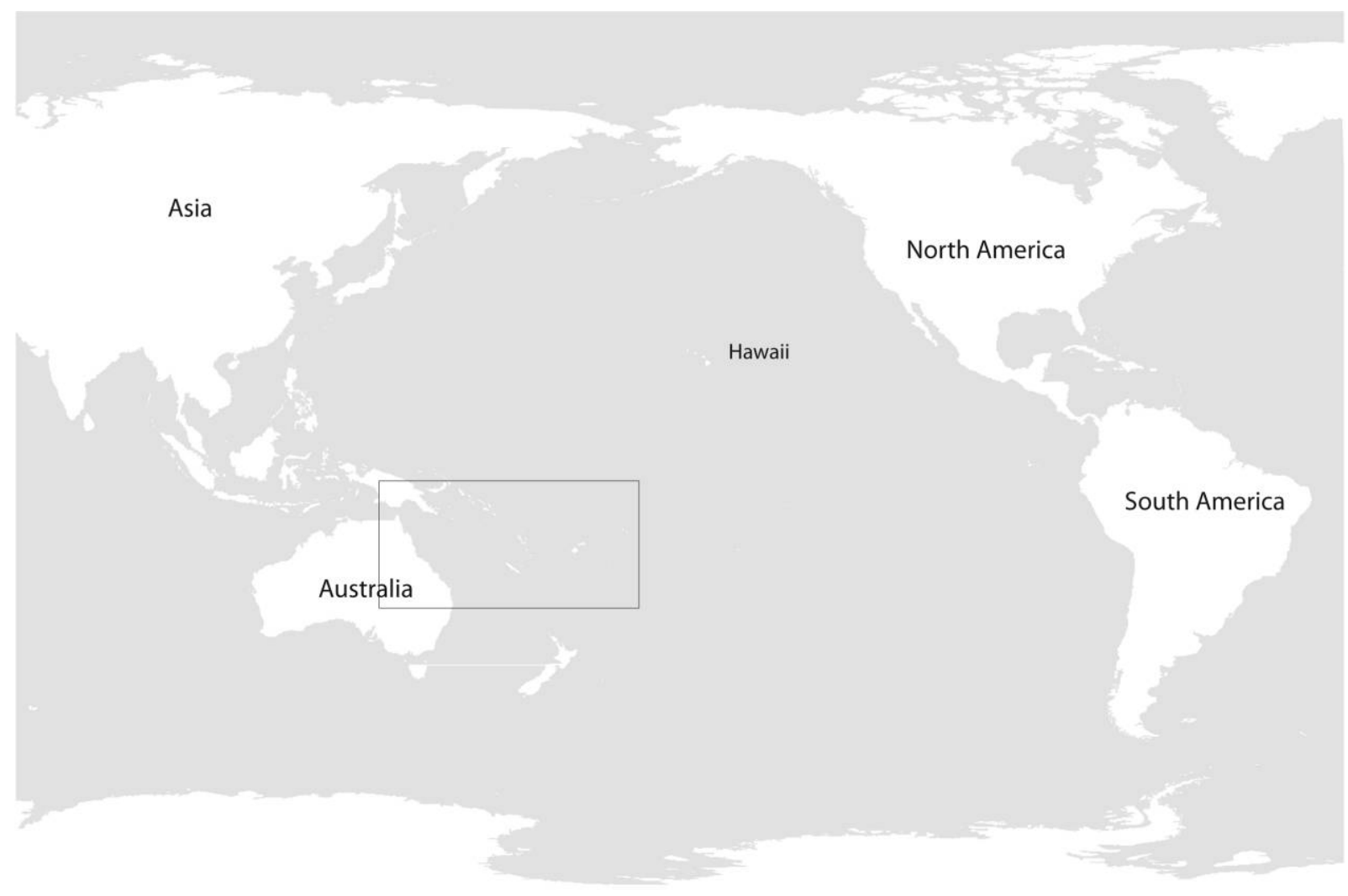

Figure 1. Map of the Pacific Ocean showing the central location of the Hawaiian Islands and the insert area for figure 2. Prepared by Mark Hauser.

of prestige goods. From archaeological evidence and ethnographic parallels among descendant communities, socially meaningful artifacts probably included many symbolic objects. Lapita prestige goods include the impressive Lapita pottery elaborated with beautifully executed geometric dentatestamped decoration, sometimes on quite large forms; personal decorative items of shell; probably bird feather and woven products; and perhaps obsidian and stone adzes.

Lapita pottery carried rich symbolic meaning (Summerhayes 2000, 2001). The upper parts of the pots were decorated before firing by straight and curved toothed stamps impressed into the wet clay (fig. 3). Simplified versions of Lapita designs were produced by linear incision rather than stamping and may represent domestic rather than ritual vessels (Spriggs and Bedford 2013). The largest pots, however, would have required considerable skill both in their slab construction and in their elaborate designs that often incorporated anthropomorphic heads and geometric infilling. Such pottery with complex iconography probably served ritual functions. The earliest pots carry complex designs produced by the finest dentate stamps. Later Lapita pots exhibit coarser stamping and simpler designs, suggesting a decline in decorative skill as the salience of the iconography faded (Best 2002).

Despite similarities in execution and iconography, which were broadly spread through the Lapita zone, the vast majority of Lapita pots were locally manufactured at most Lapita sites. The detailed provenience study of 112 vessels from Teouma on Efate Island in Vanuatu (Dickinson, Bedford, and Spriggs 2013) shows that only $11 \%(n=12)$ were imported, at least $8 \%$ from the neighboring archipelago of New Caledonia and some 3\% from islands farther north in the archipelago or beyond. The imported pots were no finer or more distinctive than the local pottery that was the bulk of the inventory. Many alternative production locations, where iconographic patterns were copied, would have eliminated an effective bottleneck.

Marine shell ornaments are found in Lapita sites and represent a diverse but standard inventory across the Lapita range (Szabo 2010a, 2010b). Prominent are Conus anklet/bracelets of shell segments sewn together (Bedford et al. 2010:156), narrow Conus rings and beads, Tridacna bracelets and rings, long beads of Tridacna and Spondylus shell, and various pendants. Many shell elements may have formed composite ornaments. Although specialized manufacturing of shell ornaments for exchange is likely (Kirch 1988b), in more recent large-scale excavations shell manufacturing appears to have been widely distributed, and so production would have been difficult to control. Although some forms would have required considerable skill and time to make, no obvious control points existed in their production or trade.

Feathers were probably also important prestige items among the Lapita. The extensive use of feathers in personal 


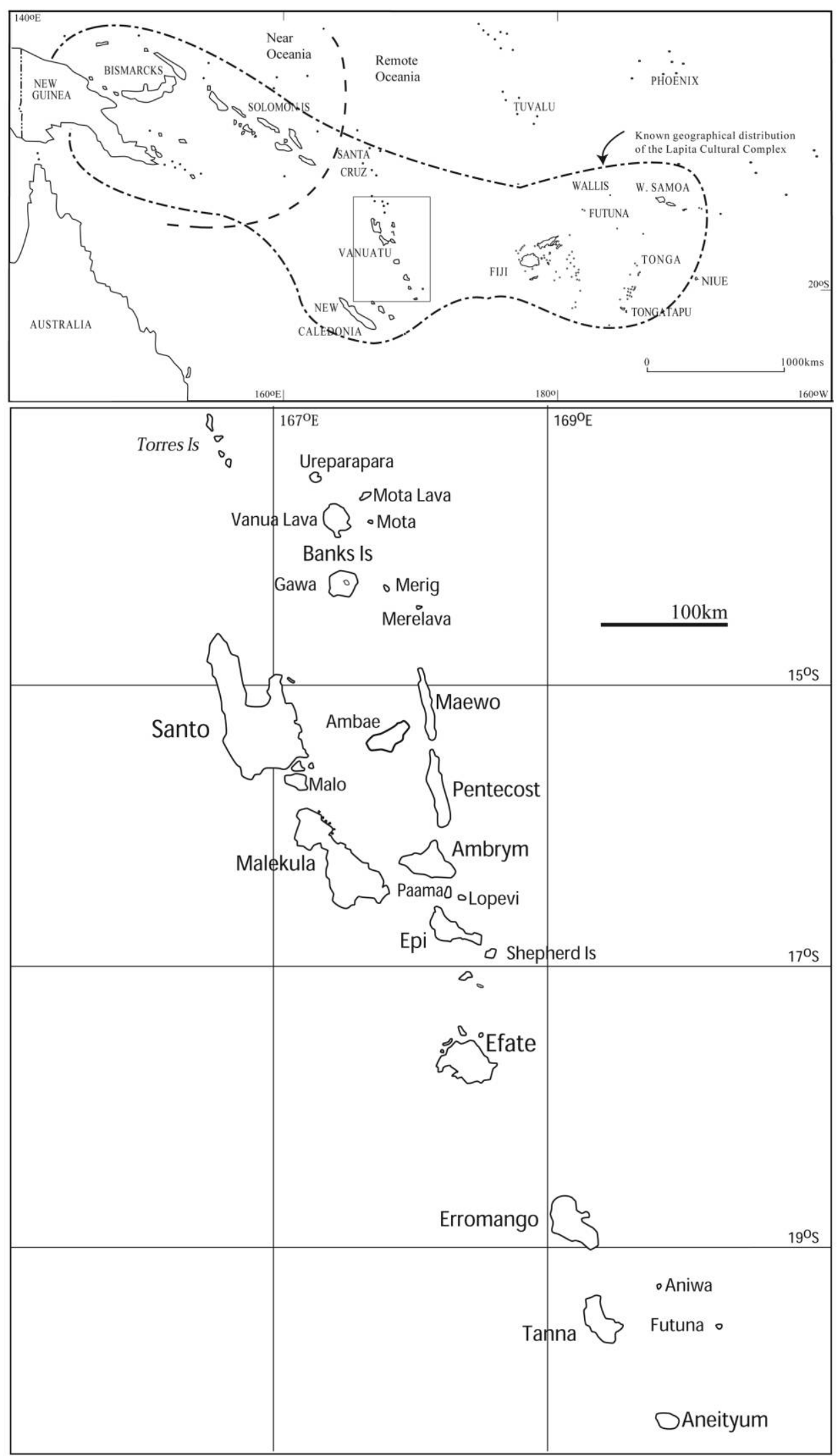

Figure 2. Maps of the spread of the Lapita cultural complex and of the Vanuatu archipelago. Prepared by Stuart Bedford and Mark Hauser. 


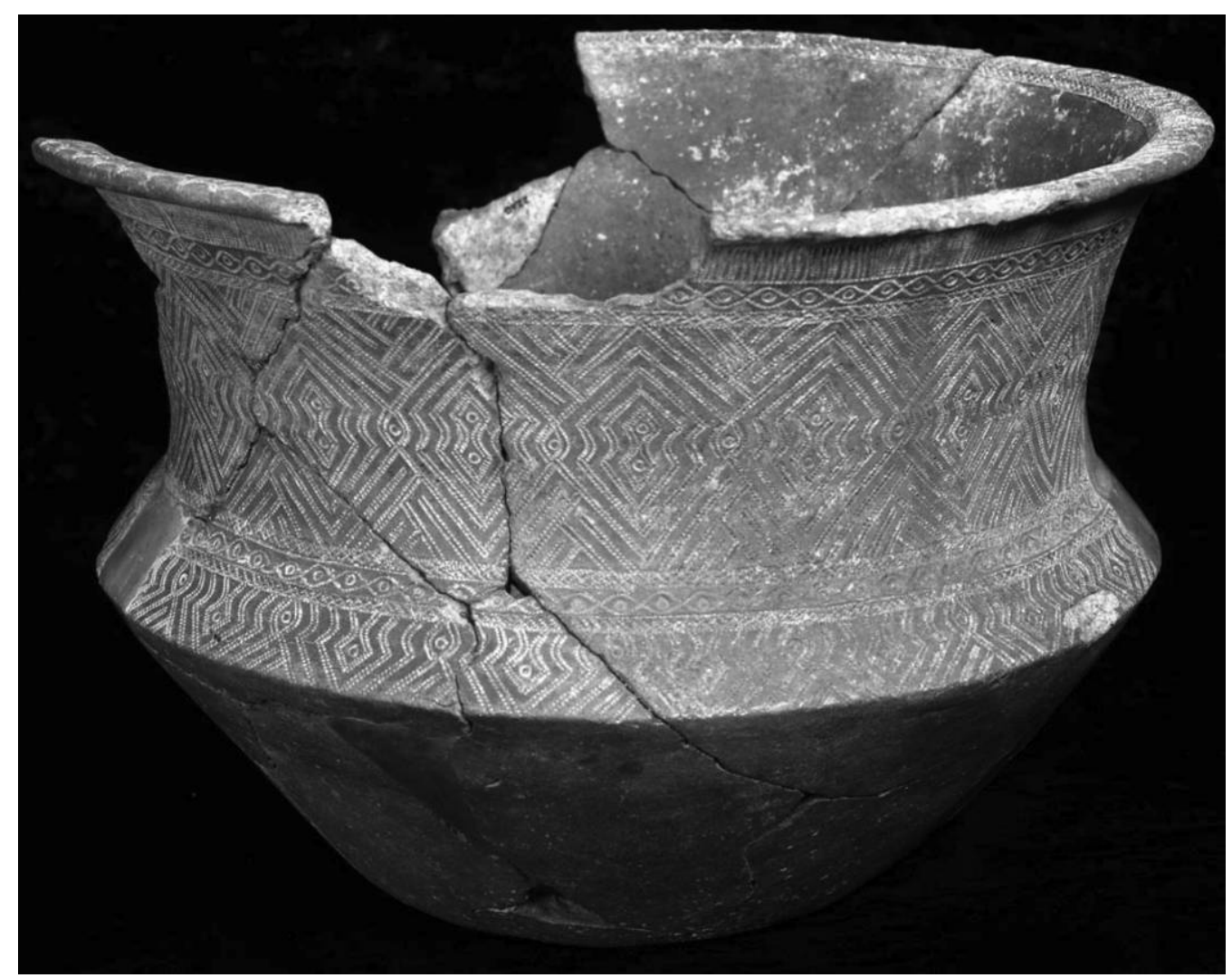

Figure 3. Example of a decorated Lapita vessel (full height, $21.5 \mathrm{~cm}$ ). Photo by Stuart Bedford. A color version of this figure is available online.

decoration is known ethnographically among descendant Pacific groups, and trade in feathers was common historically (Swadling 1996). In light of the iconography on the Lapita pots and the faunal remains of nonfood bird species (Stuart Hawkins, personal communication), brightly colored feathers probably served for headdresses and other personal ornaments. Many dramatic bird species were distributed across the region, and their colorful and exuberant feathers were probably highly valued. On the basis of ethnographic analogy and linguistic reconstruction, fine ceremonial mats and bark cloth could also have served as prestige goods, although they are unlikely to have survived archaeologically. Many sources for the feathers and mats would have precluded effective restrictions to flows.

Other possible prestige goods included obsidian tools and metavolcanic adzes, the former often obtained from considerable distances and well-attested archaeologically. The extensive (but low-volume) movement of obsidian, which comes from sources in the Bismarck archipelago, has been thought to be socially significant (Kirch 1991), and obsidian flakes were the only archaeological material that Friedman (1981, 1982) used to model Lapita prestige-goods exchange. We argue, however, that Lapita obsidian is an unlikely prestige object, because the small and minimally modified flakes would have been unsuited to carry social meaning (Sheppard 1992). The small and simple stone adzes, sometimes traded from island to island during the Lapita period, also seem unsuitable for display.

Did bottlenecks exist in Lapita prestige-goods exchange? Many items must have served in Lapita society to mark status with meaning. These objects were both locally available and obtained from a distance. All prestige goods, including the pottery, feathers, and stone, had local alternatives, which meant that they were virtually uncontrollable. The skilled labor invested in the most elaborate Lapita pots or the best shell pieces may have marked distinction, but control over these media would have been at best only partial. Neither the clay or filler for the pots nor the shells would have been sufficiently limited in availability to constrict production. The skills needed to manufacture the shell jewelry and the smaller pots were technically quite simple so that many crafters could have made them, although admittedly of variable quality (Chiu 2007). Everyone would have been able to access Lapita pots or shell pieces, although some distinction would still have been gained by having objects of the highest quality and size (cf. Clark 2007). We conclude that bottlenecks (effective 
constriction points) largely did not exist in Lapita commodity chains, with the consequence that the political economy was open and competitive.

Alternatively, the ownership of sailing craft and organizing specialized open-ocean crews could have offered would-be chiefs partial control over the movement of goods (Hayden 1983; cf. Malinowski 1922 and Brunton 1975). We imagine that distant voyaging created some potential for a small-scale hierarchy within Lapita groups but that local alternatives for status objects and the lack of a property system to mobilize staples would have made such a political economy only weakly channeled to support power relationships.

Long-distance symbolic relationships among Lapita groups were apparently more significant than a controlled trading economy. The key appears to have been local craftspeople knowing an elaborate and broadly spread iconography with elements of sacred knowledge held by a few initiates (Chiu 2007). Able to handle technically difficult production steps and knowledgeable of iconographic intricacies, gifted specialists produced the largest and most elaborate Lapita pots (Clark 2007), probably in ritual acts, offering only limited potential control by political leaders (cf. Spielmann 1998). An example of the ritual acts of Lapita production could be the unusual overpainting that obscured original dentate designs (Bedford 2006a). Perhaps part of a secret society (as known ethnographically for descendant Pacific societies), the knowledge of powerful symbols could have traveled more than actual pots (see Hayden and Villenueve 2013). Control of ritual knowledge, however, would have been largely situational and so difficult to extend to political power unless materialized by controllable objects.

Lapita tattooing may have been linked to shared symbolic representations that were more likely to build group identity than political power. Decorative motifs on Lapita pottery include human heads with elaborate geometric patterns probably representing decorative bodily modification (Green 1979; Summerhayes 1998). Skills in tattooing, for which the distribution of obsidian is perhaps a proxy, may have supported a weak political hierarchy based on sacred knowledge. The obsidian graver may have served for scarification or tattooing to carry such symbolic meaning (Kononenko 2012). But alternative materials, such as bamboo, served well for scarification, and so control of obsidian exchange could have been of little significance. Ceramic and obsidian trade was thus probably simply a symptom of what was important, the iconography that early on linked societies across an open, oceanic realm. We visualize Lapita as a competitive and rather accessible political forum that was the engine driving rapid colonization of the Pacific Islands. Leaders may have gained rank on the basis of success as navigators, traders, and discoverers, but exclusion was most probably quite limited, such that all people potentially could have participated openly.

Toward the end of Lapita, long-distance exchange disappeared, and the design system on the pots became simplified, indicating increased regionalization. Cultural diversification increased as the original "supercommunity" (Gosden and Pavlides 1994: 168) became diluted, marking the end of an identifiable and widespread Lapita culture. Diverse pottery styles replaced Lapita across its extensive distribution, certain shell ornament types dropped out of use, and what was a single Proto-Oceanic language began to break up into archipelago-specific subgroups. Across their range, scattered Lapita pioneering populations, who relied on high levels of interaction, grew into larger selfsustaining communities (Pawley 1981; Spriggs 1997a:152-162). As populations grew and became more locally distinct, the support for long-distance travel declined-spouses were available locally, and exotic goods were increasingly replaced by local equivalents. The continuing story is represented well by the prehistoric sequences of Vanuatu.

\section{Vanuatu}

The sequences of the Vanuatu archipelago exemplify postLapita societal transformation in the western Pacific. The modern state of Vanuatu consists of 14 main and many smaller islands spread north to south from the Solomon Islands toward New Caledonia (fig. 2). Around 3000 BP, Lapita groups colonized these unoccupied islands, among the first to be settled outside Near Oceania (Bedford 2006b). Colonization involved distant voyaging; the initial journey across open ocean from the Solomon chain to the Reef-Santa Cruz group exceeded $300 \mathrm{~km}$. Post-Lapita changes involved a simplification of societal structure, a settling in to local conditions, and the establishment of local corporate groups, eventually in some locations with hierarchical polities. We believe that the shift to and intensification of agriculture formed a new political economy based on local conditions that, to some measure, allowed the mobilization of staples within systems of property rights.

Changing subsistence characterized the Vanuatu sequence. Extinctions occurred in the endemic fauna; the land crocodiles and large land turtles disappeared within a few hundred years of settlement (White et al. 2010), as did many bird species (often flightless) and fruit bats. Populations began to concentrate increasingly on domesticated pigs and chickens for protein, the former requiring agricultural intensification to feed them. ${ }^{3}$ Many food crops found in Vanuatu were Lapita introductions, including root crops (yam and taro), bananas, and other fruit trees (Horrocks and Bedford 2005, 2010; Horrocks, Bedford, and Spriggs 2009; Osmond 1998). Studies of reconstructed vocabulary at colonization reveal various agricultural practices (swidden agriculture, fenced gardens, and yam mounds) but no early vocabulary for irrigated agriculture (Osmond 1998:138-140). Reduced size ranges of marine shellfish and pollen and geomorphological evidence of

3. Details appear in Stuart Hawkins's forthcoming PhD dissertation at the Australian National University. 
hill-slope erosion document environmental changes and apparent agricultural intensification.

Mortuary practices reveal compelling evidence for a changed political economy. Starting with the Lapita cemetery of Teouma on Efate Island, central Vanuatu, complex burial rites involved manipulating skeletons, such as removal of heads, and other skeletal elements suggest extended revisiting of burials. The cemetery was a place where ancestors were encountered as participants in a living cross-generational society (Valentin et al. 2011). In the cemeteries of the succeeding 2 millennia, simple inhumation replaced these complicated Lapita rituals. The burial of intact bodies represents a shortening of mortuary activities to a single primary event, representing a changing societal relationship between the living and the dead. Descent rather than group membership was emphasized (cf. Thomas 2001 for British Neolithic funerary practices). The concern, we suspect, was to establish land inheritance through descent from particular ancestors.

Across this transition, population increase created more sedentary, island-specific lifestyles. Settlements became larger, and densities increased. Some settlements were abandoned, apparently due to resource depletion, while settlements shifted to island interiors, opening up new lands for agriculture. After a millennium, abandoned settlements were reoccupied, marking a transition to full-land occupation (Spriggs 2010). As daily life became focused locally, exotic goods and associated religious ideas of Lapita were no longer salient. Chiefs had to find other bases for power or were destined to lose it. In fact, the post-Lapita Vanuatu groups appear to have taken a striking egalitarian turn. With extensive land available for settlement, if a leader became overly assertive, people could move away. To attract followers, chiefs emphasized competitive feasting that required the mobilization of staples.

Within the past 1,000 years, the number and kind of grave goods increased and the burial ceremonies became elaborate, suggesting some emergence of hierarchy. Many of the mortuary forms in central and southern Vanuatu show Polynesian influences with references to chiefs. The practice of ritual sacrifice of individuals accompanying chiefs in death has direct Fijian parallels (Valentin et al. 2011:62). The significance of Polynesian and Fijian influences is not, however, to be found in trying to map these patterns onto Vanuatu practices, but the presence of hierarchically structured Polynesians in the archipelago and renewed long-distance contacts with Fiji changed how Vanuatu chiefs could operate. Practices were not borrowed from outsiders but rather provided a new arena for display in ways not seen previously (Valentin et al. 2011).

Clear hierarchies developed; large numbers of prestige goods accompanied dead chiefs and their sacrificed wives and retainers. Shell items appear dramatically in chiefly burials in Aneityum and most extravagantly in the burial event found on the islet of Retoka off Efate. Here, according to oral history, Roimata, the influential chief of a broad region, was buried along with at least 45 others who were ritually killed and then arranged formally around his body. Bodily adornments in- cluded shell and circular pig tusk armbands, shell bead strings and belts, and other special items. According to oral tradition, this cemetery materialized a newly formed chiefdom (perhaps the largest in Vanuatu), as chiefly influence and, perhaps, control extended across the island of Efate and smaller islands (Garanger 1972). Staples mobilized by chiefs probably supported the recruitment of specialized warriors needed to back up such influence, as documented for the Polynesian island of Futuna (Kirch 1976). Where irrigation did not exist, conquest warfare could expand the region under a chief's control.

Increased social distinctions involved fundamental local changes in the political economy to one based on staple mobilization. As agricultural systems were intensified, contrasts emerged among islands across Vanuatu based on their degree of institutionalized power linked to potential property constrictions. On the southern island of Aneityum and in scattered locations elsewhere, groups constructed irrigation systems to intensify agriculture (Spriggs 1986). Increased erosion caused by pioneering agriculture on upland soils created new alluvial deposits in the lowlands of some islands where the offshore topography and reef conditions allowed (Spriggs $1985,2010)$. Where the new alluvium built up, farmers constructed large agricultural complexes with irrigation canals, creating an engineered landscape in which chiefs could claim ownership and mobilize staples as rent. The result was the emergence of territorial chiefdoms like those in Polynesia.

On other islands to the north, a more open political hierarchy of grades emerged, suggesting a property system that did not involve a permanent, built agricultural infrastructure. But it could be highly productive, creating the possibility for surplus extraction where property rights could be established. Ethnographic descriptions from the descendant groups on Malakula illustrate how this could be done. Deposition of volcanic tephra from eruptions created highly fertile soils that supported intensified dryland farming. A person wishing to take a grade in the political hierarchy sponsored a large ceremony that required the killing of full-circle tusked pigs - knocking out the upper canines allowed the lower ones to grow and circle back into the jaw. Progressively higher ranks required more elaborate feasting events and the killing of more pigs. These pigs were labor intensive, requiring hand feeding to protect their tusks. The tusks of sacrificed pigs became bodily decoration of elite persons and key elements of ceremonial masks and human-form sculptures, known as rambaramp in southern Malakula (Deacon 1934). These sculptures were life-size likenesses of dead chiefs with their skulls used to model the heads. These skull sculptures helped establish lineage histories of chiefs within a new forged hierarchy concerned with rights to surplus.

The construction of pig altars and large standing stones at ceremonial plazas commemorated the chiefs who erected them and their associated grade-taking ceremonies (fig. 4). Such monuments required social labor and its coordination to haul and erect the stones, which were often carved. The erection of large stone monoliths made permanent the mem- 


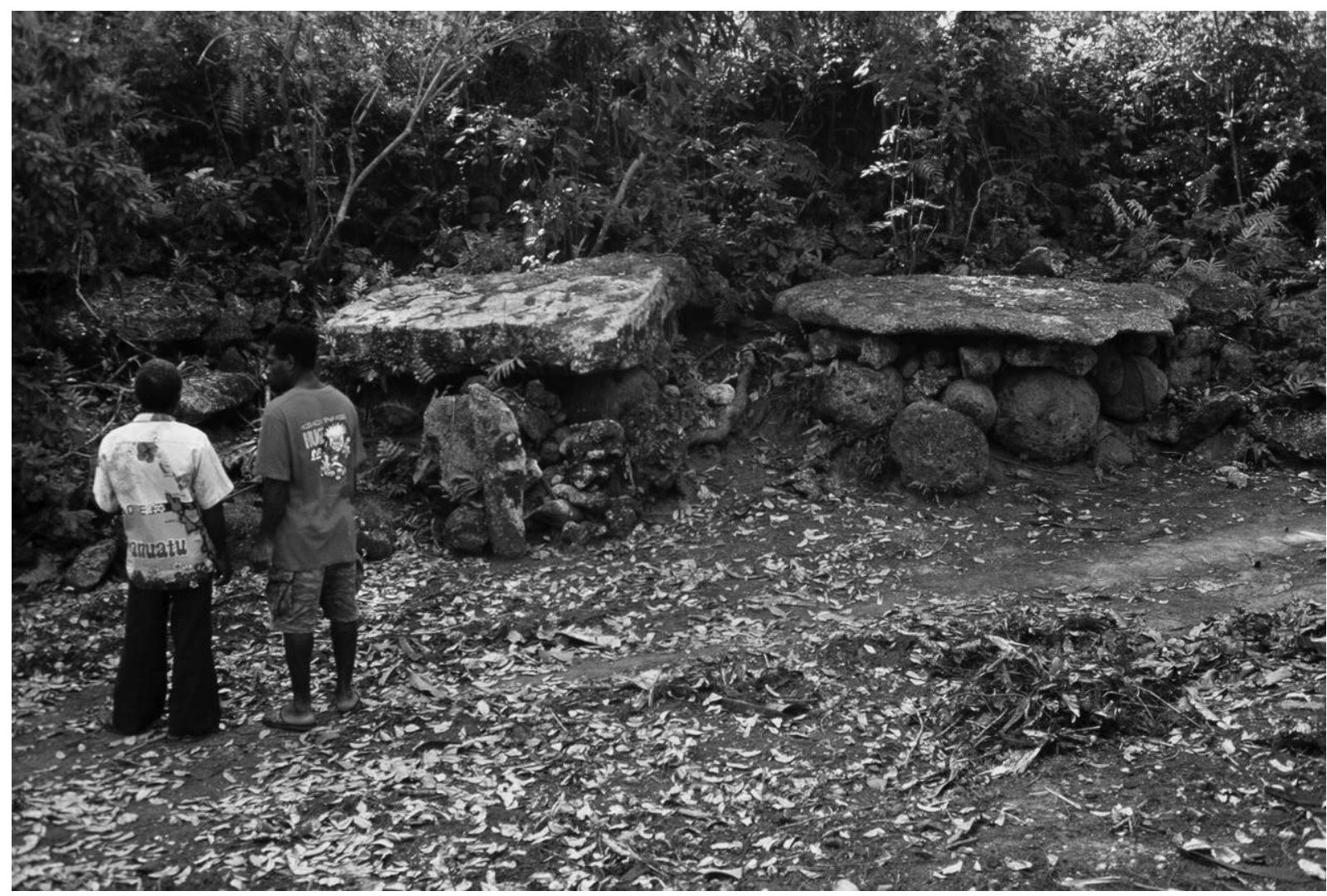

Figure 4. Stone pig-killing tables, Peterhul nasara (ceremonial ground), Vao Island, Malakula, 2003. Photo by Stuart Bedford. A color version of this figure is available online.

ory of display events as a means to institutionalize the interpersonal labor and land relationships, on which an elemental staple finance system became based. Polity sizes of these societies would have rarely reached a thousand. They were unstable and difficult to maintain, and hierarchy was often challenged. In some parts of northern Malakula, the entire male community of a particular generation took a grade at the same time, seemingly to deny hierarchy based on anything but age (Layard 1942). Women too could take grades in many parts of northern Vanuatu. There were also areas of Vanuatu where intensified agricultural systems did not develop because of ecological constraints. Here, no strategic points of chiefly control existed, and more egalitarian political structures were prevalent.

Variation in political economy across Vanuatu apparently resulted from diverse conditions of intensification that generated distinct property systems and alternative means to mobilize staple surpluses. The extent and nature of hierarchy across the islands of Vanuatu were highly variable, from Polynesian-like chiefdoms based on irrigation to relatively egalitarian age-graded societies. When feasible, property systems were materialized in the engineered landscapes of irrigation systems owned by the chiefs. Where irrigation was impractical but land was still highly fertile, chiefs could build a ceremonial landscape with labor, and monuments held the memory of social events and encumbering obligations. Construction of monumental places established permanent chiefly positions and associated rights to labor. Across Vanuatu, a mosaic of power emerged that was both variable and dynamic. People became tethered to place primarily by attractions of highly productive agriculture and associated ceremonial elaboration. If a chief became too assertive in demands for surplus and labor, people could vote with their feet, moving to perhaps less desirable locations but ones with more generous chiefs or no chiefs at all.

Although objects of wealth were increasingly important to mark distinction in Vanuatu, this development was secondary because crafts had few control points in manufacture and trade. Items of distinction were made of local materials and produced by relatively simple technologies. Control over access to materials or their manufacture would have been difficult. As a competitive wealth finance system developed over much of northern Vanuatu, the focus of wealth became based on raising pigs with artificially engineered full-circle tusks. Such a system was possible only because of the highly productive agricultural soils, and the limiting factor was the labor invested in raising the full-circle tusked pigs, which could not forage for themselves. 
To conclude, as Vanuatu populations expanded, the possibilities for chiefly control increased irregularly. Competitive feasting was perhaps a common pattern for establishing hierarchical relationships among social groups, with the limits of chiefly power set by the extent to which they could extract surplus and fund elaborate ceremonies (cf. Beck 2003). Control of irrigation works on some islands was clearly an attractive route, producing Polynesian-like chiefdoms. But many Vanuatu islands are naturally fertile, and the basis for chiefly control was problematic, requiring legitimation through ceremonial elaboration and an ideology of reciprocity.

Incidentally, for the Solomon Islands, the archipelago to the north of Vanuatu, Bayliss-Smith and Hviding $(2012,2014)$ discuss malaria as a major constraint to population growth and therefore to agricultural intensification (cf. Kirch 2000:8384). In the Solomons and Vanuatu, a significant gradient exists in malarial incidence from the malarial north to the near malaria-free southernmost islands and from lowland to highlands within some islands. Where malaria was prevalent and the population remained low, agriculture was not intensified, and so the built environment associated with property systems was absent. Across island Melanesia, we envision a mosaic of societies with differentially intensified landscapes that created a full gradient in the power based on property. The islands in Vanuatu that developed the most hierarchical chiefly systems had intensive irrigated agriculture; these were relatively unaffected by malaria. New Caledonia, for example, is malaria-free, as is Fiji, the next archipelago to the east, and all of Polynesia. Powerful chiefs could operate staple finance economy based on intensive taro irrigation. As people colonized Fiji and deeper into Polynesia, the development of staple finance economies created full resource use within circumscribed productive zones (Carneiro 1970).

\section{The Hawaiian Islands}

The Hawaiian chain of six major islands is located just below the Tropic of Cancer at the northeastern apex of a triangle defining the extent of Polynesian islands in the central Pacific (fig. 1). The Hawaiian Islands are unusual for both their large sizes and extreme isolation. Polynesians colonized the Hawaiian Islands late, about $1000 \mathrm{BP}$, and, with the exception of a short period when oral traditions mention contacts with Tahiti, the Hawaiian Islands remained physically remote until "discovery" by Captain Cook. Polynesians found rich and extensive volcanic and alluvial soils, to which they brought domesticated plants and animals to realize a great productive potential. Although dynamics in the political economy were similar to those described for the Lapita and Vanuatu, the rich and extensive land areas permitted population growth unconstrained by malaria and eventually led to largescale staple mobilization that supported the formation of prehistoric pristine states. We follow here the footsteps of scholars who have analyzed the singularity and importance of structural transformations in the Hawaiian case (Flannery and Marcus
2012; Hommon 2013; Kirch 2010, 2012; Sahlins 1958, 1985), but we emphasize the dynamics of the Hawaiian Islands' political economy as foundational to its evolutionary change.

The developments in the political economy and political organization in Hawai'i followed a trajectory already familiar from Vanuatu. Not unlike the Lapita colonists of Vanuatu 2 millennia earlier, a small group of Polynesian explorers would have found and occupied the Hawaiian Islands. Initially reliant on coastal fishing and scattered farming, they shifted more toward simple agriculture, expanding their settlements inland onto upland soils. Nothing during these early stages suggests effective control points that could have helped leaders mobilize surpluses. We de-emphasize the founding structural principles of inequality as determining subsequent social evolution, looking rather at the historical conditions created through the Hawaiian Islands' long sequence of changes.

As populations grew, we can assume that the Hawaiian Islands filled in with settlements increasingly dependent on intensified agriculture and associated facilities. This process of intensification on isolated islands circumscribed the built landscape, creating the basis for a property system used to mobilize surplus (cf. Carneiro 1970; Kirch 1988a). The filling in would have limited a local community's options, creating control opportunities in local subsistence that offered chiefs opportunities to mobilize surplus.

Clearing the upland forest accelerated erosion and created a rich alluvium on the valley bottomlands (Spriggs 1997b). Wetland taro agriculture had probably been used since first colonization, but sometime after 800 BP Polynesian farmers expanded it to cover new alluvial soils spotted throughout the Hawaiian Islands. Although the chronology of irrigation deserves further study (Bayman and Dye 2013), some finegrained data are available (Kirch 2010:143-145; McElroy 2012). The extensive engineered landscapes came to include irrigated pondfields for taro, fishponds, tree groves of bananas, breadfruit, and coconut as well as newly constructed religious monuments, roads, and division walls. In one exceptional case on Maui, historical data reveal that a chief organized people to carry quantities of soil to cover barren lava flows to create productive irrigated farmlands on a sterile landscape (Handy 1940:110). Although commoners retained broad access to local resources (Dye 2010), elites controlled the most productive staple-producing lands.

The new political order established taxing units (ahuриа' $a$ ) with overarching ownership vested in the paramount, as his close kin and supporters received units as fiefs and the commoners received subsistence plots. The ancient lineage system through which commoners claimed rights to land was supplanted by a feudal-like system in which commoners gave obligated labor and material in return for access (Hommon 2013; Kirch 2012). Especially on the eroded western islands of $\mathrm{O}^{\prime}$ ahu and Kaua'i, where irrigation was most developed, subsistence plots in the irrigated systems were divided among farmers (Earle and Doyel 2008; fig. 5). Under a manager's oversight, commoners were obliged to work plots and fishponds 


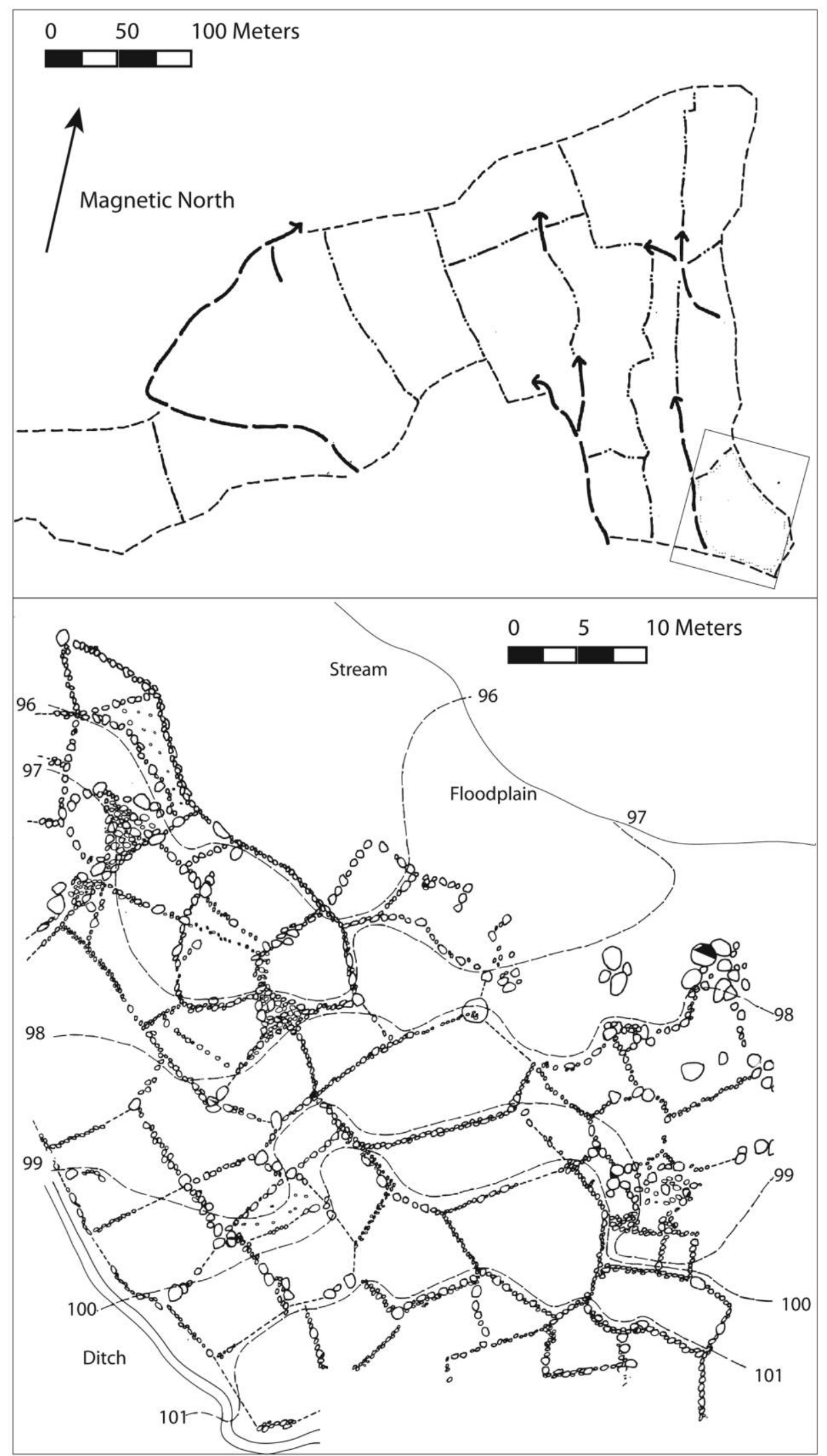

Figure 5. Abandoned irrigated taro field complex at Ha'ena, Kaua $i, 1971$, showing the divisions into management sections, irrigation ditches, and a section of walled terracing (Earle 1978, figs. 6.3, 6.4). Prepared by Eliza Earle and Mark Hauser. 
set aside for the chiefs, generating surpluses to support chiefly objectives (Earle 1978). The intensified irrigation facilities were developed wherever possible, and they became highly productive zones, although they were but a small fraction of the total land area (Earle 1980). Concentrated in the lower valleys, the largest systems were easily dominated by chiefs, serving as bottlenecks for staple production (McCoy and Graves 2010). But commoners were not without agency even within these situations. They could, and did, move between communities when exploitation became extreme. Many small irrigation systems were located in the remote backs of large valleys and on small streams, where commoners may have farmed relatively free from chiefly oversight (Earle 1978).

The potential for irrigation was much lower on the younger (less eroded) eastern islands of Maui and Hawai'i, where valleys and river systems were few (Ladefoged et al. 2009). Here, the staple-based political economy emerged first in core zones and then expanded through the building of extensive dryland systems. Walls and terraces subdivided dryland fields, presumably defining property rights and obligations, much as in irrigation complexes. Although dryland zones were less productive and more risky, their productivity for pig husbandry may have been high (Dye 2014, with commentary). Because the dryland fields produced mainly sweet potato, an ideal pig food, these fields could support large pig herds, a moveable wealth critically important as ceremonial offerings and gift payments. Dryland farmlands were not equal; some areas were more productive, lower risk, and substantially more engineered with terraces than others (Ladefoged and Graves 2008). Like the irrigated areas, these core dryland zones would have served as control points producing staples and staple-fed pigs for the political economy.

The state-like polities of Hawai'i were formed by conquest that depended on both warrior and priestly specialists (cf. Carneiro 1970). To develop individual large-scale polities, mobilized resources were poured into a warrior elite, power specialists expanding the spatial extent of their polities (Kirch 2010). Structurally, conquest helped to formulate an ideology of the stranger king distant from commoners and linked to divine powers (Sahlins 1985). Territorial conquest broke local community ownership rights, creating an overarching title held by the ruling paramount. Where based more on intensive dryland farming (as on the Big Island of Hawai'i), the physical extent of the polities had to be greater, and a new institutional order became based more on those warriors and on a priestly class attached to the paramountcy (Kirch 2010).

To institutionalize the regional Hawaiian chiefdoms and those elsewhere across Polynesia, social labor (mobilized by chiefs) built religious monuments as a hierarchy of temples that marked the landscape and determined responsibilities of individual communities to support annual ceremonies (Kolb 1994). The eventual creation of divine kingship was dependent on elaborate ceremonies, supported by surpluses made possible by the large island areas and their productive soils
(Kirch 2010). The conclusion is that state formation created a distinctive class of rulers who asserted ownership over community lands, their facilities, and staple production. A retinue of specialists involved in land management, warrior might, and religious sanctification was supported by surpluses and in turn worked to support the institutions of chiefly rule (Earle 1978).

Prestige goods were an essential part of the Hawaiian political economy and reinforced a class-based ideology. The Hawaiian objects included the famous feather cloaks, helmets, and other paraphernalia of the ruling chiefs, clothes of the gods (Earle 1987). Additionally, whale-tooth pendants, special woven mats, elaborately decorated tapa cloth, beautiful wooden bowls and utensils, weapons, and elaborately carved religious sculptures were part of the chiefly and religious material culture. By and large, these items were made of materials that were broadly available, and the technology of manufacture was not exceptionally complicated, although highly skilled and knowledgeable specialists would certainly have been involved. These items were not linked to a world system of trade because of the extreme isolation of the Hawaiian Islands. Rather, the materials for prestige goods were obtained locally or from adjacent chiefdoms, and then craftspeople supported by the chiefs produced these items. This is in marked contrast to Europe, where the most important prestige goods were made of metal, amber, jet, and shells obtained from great distances. The model of a prestige-goods economy formulated for Europe, therefore, is not applicable in its specifics to the Hawaiian case.

The production and trade of symbolic paraphernalia was an extension of staple finance, not an independent mode of economic mobilization (Cordy 2003). In the annual collection from communities, the high chiefs demanded special products like bird feathers, bark cloth, and dyes. Artisans who transformed these materials into symbolic objects were supported within the chief's household or received land in return for their skilled labor. The prestige goods thus converted staple surplus into objects of significance used to define the status of chiefs and to assert their religious legitimacy. The feathered cloaks were especially important, apparently produced for the paramount chief, who distributed them to supporting chiefs. These special goods became props in the ceremonies and dress of the high chiefs as god-kings. Additionally, the production of warrior canoes and special weapons helped to solidify control over the warriors, so important for conquest.

Another potential point of control existed over the technology used to manufacture symbolic objects and weapons. The basalt used for adzes (for woodworking) was available on all islands, but high-quality basalts appear to have been restricted to certain sources and traded between islands (Lass 1998). These traded basalts were concentrated in elite residences and religious shrines (Kirch et al. 2012), suggesting that chiefly networks dominated their distribution and use to sculpt god images and other paraphernalia for temples 
and to build warrior canoes and other weapons. The interpolity trade may have reinforced control over the manufacture of critical objects, but, because of local alternatives, it would not have been a primary bottleneck in the political economy.

To summarize, the low-density colonizing populations of Hawai'i probably formed a fairly open society initially, although ideas of status were surely retained. The subsequent population expansion filled the landscape and intensified its use, creating circumscribed zones of highly productive agriculture claimed by a ruling elite. Substantial surpluses supported managers, warriors, and priests in the process of institutional reformulation. The agency of commoners should, however, never be discounted. As in Vanuatu, alternatives for movement within and between the Hawaiian Islands would always have mitigated chiefly autocracy. A bargain between chiefs and commoners created surplus extraction that, at the same time, required chiefs to maintain a moral economy with well-managed farming systems, access to wild resources of uplands and sea, and ceremonial legitimacy. Although the chiefs of Hawai'i crafted exceptional central power, the need for the labor power of commoners never made them simple pawns in the process.

\section{Conclusions}

A political economy approach to prehistoric sequences offers a foundational understanding of alternative pathways to complexity. Along with ecological methods, the theory of political economy has strong general applicability for understanding social evolution. The political economy in all of its manifestations financed the development of sources of power that extend chiefly authority and solidify polities with populations in the high hundreds, thousands, and tens of thousands and beyond. The Marxist tradition of historical materialism appears to have exceptional promise for explaining long-term change, and we argue for a renewed elaboration of this established tradition of scholarship, using the rich archaeological record now being produced.

The prehistory sequences of the Pacific illustrate how variation in political economy (an outcome of ecological, topographic, epidemiological, technological, structural, and other historical factors) created the engine that resulted in wide variability in political forms, despite common historical and technological conditions. Within a few thousand years, the people of the Pacific developed political institutions that ranged across the spectrum from egalitarian societies to local chiefdoms, regional chiefdoms, and state-like polities. Our paper highlights different bottlenecks in the production and distribution of staples and wealth goods as critical to generating diverse political forms. Alternative control points varied in their potentials to channel surplus flows. Whether it was canoes for distant travels or military adventures, the construction of monuments materializing a ceremonial landscape, or the engineered facilities of intensive (often irrigated) agricultural systems, the establishment of overarching systems of ownership created some opportunities for surplus extraction. At the same time, commoners maintained strong (although variable) abilities to counter or benefit from central authority. The patterns observed are highly dynamic and constantly negotiated.

We propose that, for Lapita, the uncertain bottleneck was based on voyaging with wealth-like exchanges of esoteric knowledge. Subsequently for the western Pacific, a critical constraint to power resulted from density-dependent malaria. In Island Melanesia, the most powerful chiefdoms were based on staples mobilized from engineered landscapes without malaria. In much of northern Vanuatu, no obvious control points existed, but, given the volcanically enriched soils suitable for dry land agriculture, agricultural production became channeled by chiefs into competitive pig production for feasting and ritual exchange. Ambitious individuals could manipulate such a system by borrowing and lending high-value "engineered" pigs, but it was a fluid and unstable means to concentrate power. In Polynesia, where the absence of malaria meant that the demographic brakes were off, staple finance systems reached fullest potential in Hawai $i$.

The Hawaiian case illustrates clearly the dynamics by which a corporate society can develop strict stratification based on ownership of land. A recent distinction between corporate and network societies provides a useful reformulation of political economy in prehistory (Blanton and Fargher 2008; Blanton et al. 1996), but the Hawaiian case shows that corporate ownership of land could be largely erased by warrior might and religious ideology that ruptured structural bonds of local laborers to their land. Intensive irrigation systems developed by local communities created the conditions for surplus extraction that supported the means of social reformulation as a highly stratified society.

More generally, we have shown that by using a sciencebased method to social evolution, grand narratives become possible by drawing on the intellectual foundations of Marx and Childe. Social theories such as these help to make sense of new evidence and to provide research plans that direct our efforts to recover the needed evidence to modify these theories. The time is right for attention to the longue durée. Political economy approaches will not be stage based but will show how common processes of resource control help explain the specifics of social history. Hopefully, they may also suggest future opportunities to reduce social inequalities through an understanding of the past.

\section{Coda}

Misperceptions that the rise of chiefdoms is inevitable and that the institutionalization of chiefdoms determines a class of rulers easily surface. Neither is correct. We argue that the rise of chiefdoms and subsequent states is rather exceptional, dependent on specific conditions. The process is reversible, and the dynamics are both variable and precarious. Foundational is the political economy, but that foundation is human authored and unstable. It depends on diverse and episodic 
conditions that can just as easily increase or decline in social complexity. Alternative pathways always exist.

There are would-be chiefs waiting in the wings, and descent is never in itself enough to be accepted as a chief. Chiefs must demonstrate both their capability and legitimacy. The role is always performative. An example drawn from the death in 2011 of a chief from northern Vanuatu illustrates the indeterminacy of succession. One hundred days after the chief's death, a major ceremony represents the official end of mourning except for the close family. This chief was the eldest son of his predecessor, adopted soon after birth. The eldest biological son, a considerable chief in his own right, harbored resentment for his adopted brother's presumption of paramount status. On the ninety-ninth day of mourning, he seized the moment to organize a pig-killing memorial ceremony for his brother, at which he dispatched 10 full-circle tusker pigs. The event was commemorated by the erection of 10 megalithic stelae at his men's house. Few in the area had thought that he could carry it off. He was old and in ill health; many considered him yesterday's man. But he had spent years quietly planning for such a moment. All his debts were called in to acquire the highest-esteemed livoala pigs. Such performative acts are always risky; pigs can be promised but not delivered, and only loyal supporters necessarily want the event to succeed. When it went off as planned, one naysayer became so out of sorts that he suffered a heart attack and had to be medevaced from the island. As the 100th day dawned, the region woke up to a new undisputed paramount chief in what amounted to a pig-enforced coup d'état.

The new paramount's eldest son has paid most of the construction costs of the church in the central village and organized rebuilding of the men's house subsequent to the pig-killing ceremony. Both he and his father were prominent in the ceremonies attendant to the latter's reopening. Meanwhile, the children of the recently deceased paramount have not been idle. One was elected as the local member of parliament, and the untimely death of his party president elevated him to that role, too. He is building a large, permanent house in the central village, having gained a toehold during his father's life. Another son is a high-ranking civil servant. The open rivalry between their side of the family and that of the new paramount enlivens many a village community meeting and has led to the exchange of lawyer's letters. Chiefs are not dying away any time soon, and the performances continue. But these performances are not simply visual acts. They require strategic organization and expenditure of vast resources that test individual capacities as would-be chiefs. Elementally, these performances establish and calibrate a person's place in the political economy - a prerequisite for present and future political survival.

\section{Acknowledgments}

With support of the Australian National University, Tim Earle spent 5 months in Canberra (February to June 2012), where he lodged with Matthew Spriggs. He delivered a Golson
Lecture, which honors Jack Golson, a founder of Pacific archaeology and long-term Marxist, not unlike Australia's V. Gordon Childe. Earle wrote the lecture in conversation with Spriggs and Golson, and he decided to author the present article with Spriggs because of common interests and research in the Pacific. The Golson Lecture was delivered at eight universities around Australia and New Zealand, supported by the Society of Antiquaries of London and by local hosts, and Earle was fortunate to receive many comments. We thank particularly Stuart Bedford, Elizabeth DeMarrais, Tom Dye, Eliza Earle, Thegn Ladefoged, and Mark McCoy for indispensable comments on manuscript drafts as well as Stuart Bedford and Stuart Hawkins for specifics on Vanuatu archaeology. We are grateful to seven anonymous reviewers and Current Anthropology Editor Mark Aldenderfer, who offered pointed and productive thoughts.

\section{Comments}

\section{Lane F. Fargher}

Departamento de Ecología Humana, Centro de Investigación y de Estudios Avanzados del Instituto Politécnico Nacional, Km 6 Antigua Carretera a Progreso, 97310 Mérida, Yucatan, Mexico (lfargher@purdue.edu).26 I 15

A political economy approach to better understand long-term social evolution in Oceania, a culture area that has not played a significant role in recent anthropological theory building, should be a welcome addition to the literature. But the article by Earle and Spriggs fails to deliver. While I agree that archaeology should be dedicated to building a "science-based" understanding of human history and that the concept of "bottlenecks" can facilitate our understanding of the development of social complexity, I part with the authors on their insistence that a Marxist paradigm represents the way forward and that a science-based understanding can be achieved within this paradigm.

For me, a scientific epistemology involves developing and testing hypotheses and theories using empirical observations. Hence, a scientific approach would entail using archaeological data (from Oceania) to systematically test Marxist predictions. However, instead of testing the Marxist paradigm (as well as much of the environmental determinism of the neoevolutionist paradigm), the authors accept its assumptions and assertions unquestioningly. In the process, they ignore much important scholarship from the past 30 years. This approach brings to mind Thurston's (2010) astute observation that "without an explicit orientation toward the study of how power 'works,' ideas about political organization are often introduced simply by repeating the rationalizations of earlier approaches, read, re-read, and internalized over many decades, perpetuating a narrow understanding of the ways in which political power can be constituted and expressed" (194). 
Such narrowness, both theoretically and empirically, is on display throughout the essay. First, the political economy of bottlenecks is severely underdeveloped. Bottlenecks are considered to be accidents of environmental factors (environmental determinism) or strategic action used by chiefs to dominate society. Such an approach fails to consider the full range of behavioral implications. Drawing on the authors' example, a chief could build a fortification on a trade route, but what value does this major infrastructural investment provide if merchants simply alter their routes? Furthermore, individuals may recognize the potential costs to them of chiefly bottlenecks and work collectively (i.e., cooperate) to impede them. Thus, theoretical development on the role of bottlenecks must consider the potential responses from, as well as the limitations they potentially pose for, all members of society, not just chiefs.

In the Lapita case, when the authors failed to find an empirically verifiable bottleneck, they looked for unverifiable explanations (e.g., control over ocean-going vessels) instead of considering alternative pathways because, apparently, the material complexity of Lapita had to be the result of chiefly competition. I would argue that the data could indicate that Lapita societies intentionally selected mediums that could not be monopolized as part of collective political economy strategies that emphasized inclusive group membership (lineages, sibs, phratries, etc.; for comparative collective cases, see, e.g., Blanton et al. 1999; Leach 1954; Liu 2004; Morgan 1901; Peregrine 2001; Stein 1994; Swanton 1928).

In the Vanuatu and Hawaiian cases, the authors ignore a massive amount of empirical data to the contrary (e.g., Blanton and Fargher 2008; Erickson 1999; Lansing 1987, 2009; Lansing and Kremer 1993; Ostrom 1990; Trawick 2001; Twitchett 1979) and assume that elites benefited from population pressure and circumscription to control irrigation systems and coerce farmers. Besides the obvious problems with population pressure, Blanton and I (2008:273-274) have shown that the circumscription and exploitation model does not enjoy empirical support (collective action total regressed against exit opportunity, $r=-0.44, P<.05, n=30$ ). Empirical observations show that farmers, with limited emigration options, will negotiate, practice noncompliance, and/or rebel in order to resist elite exploitation (Blanton and Fargher 2008). Apparently, where farmers are heavily invested in the landscape, they tend to drive off or kill leaders that do not adhere to social contracts instead of emigrating. For example, in the case of Tonga (where permanent cultivation of manioc and taro occurred in fenced fields; see Cook 1967), "chiefs who did extract goods and services, regardless of return - were met with assassination or a popular rebellion that installed someone who acted more in keeping with chiefliness" (Gailey 1987:251).

In this light, it is interesting that there appears to be a geographical disconnect between intensive agriculture and a heavy emphasis on prestige goods (especially pig tusks) and conquest warfare. In Vanuatu, capital-intensive agriculture was important on Aneityum, but production and control of prestige goods (e.g., pig tusks ornaments and rambaramp) were much more important on Malakula, which the authors link to a Polynesian world system. In the case of Hawai $i$, highly intensive agriculture was common on $\mathrm{O}$ 'ahu and Kaua' $i$, but competitive chiefs, pig production, and conquest warfare figures more prominently in the descriptions of Maui and the Big Island, where dryland farming and pigs predominated. It would appear that chiefly wealth and power were disconnected from control over irrigation systems in Oceania.

Although the authors claim that they reject unilineal explanations, chiefly control of bottlenecks is the only pathway to complexity considered. I think there is much potential for developing a nonlineal perspective on complexity in Oceania, but the Marxist paradigm advocated by the authors impedes its development.

\section{Gary M. Feinman}

Integrative Research Center, Science and Education, Field Museum of Natural History, 1400 South Lake Shore Drive, Chicago, Illinois 60605, USA (gfeinman@fieldmuseum.org). 14 I 15

Earle and Spriggs make an important contribution through a selective retooling of the political economy frame and its application to three preindustrial archaeological sequences from the Pacific's past. A paradigmatic reflection is in order, as the tempo, volume, and quality of archaeological knowledge creation has outpaced the reflective construction and consensual application of effective theoretical frameworks (Carballo, Roscoe, and Feinman 2014; Kristiansen 2014). Here, I focus on theory with less attention to the cases under study, as my familiarity with Oceania's longue durée is limited.

The authors outline a suite of conceptual tenets that can be built on productively. They call for a "science-based understanding" of human history that extends from the deep past to the present. At the same time, they eschew unilinear sequences while recognizing that we should focus on the shared processes that effect long-term change along alternative pathways. The dynamic and diverse social networks and interpersonal tensions that juxtapose leaders and followers are viewed as a key, with special emphasis on the varying fiscal underpinnings of governance, leadership, and power. Although not a primary focus, Earle and Spriggs also recognize that the comparative examination of long-term human history requires a multiscalar vantage.

Of particular significance is the authors' explicit analytical consideration of nonelite agency, a conceptual step too rarely afforded by archaeologists in previous processual and political economy approaches to the preindustrial past (Feinman 2013). Nevertheless, I question the prevailing presumption that the means of production - especially land and associated investments, including terraces and water management-are, in general, directly controlled as an undergird of power. 
Agrarian intensification need not be a top-down process (Erickson 2006; Netting 1993; Ostrom 1992; Wilken 1987), as suggested for prehispanic highland Mesoamerica contexts, even where considerable differentials in power existed (Feinman and Nicholas 2012; Smith 1996:77-79).

Rather, from the perspective of collective action approaches (Blanton and Fargher 2008; Levi 1988; Olson 1965), the fiscal foundations of governance often are not grounded strictly in direct ownership but through a suite of reciprocal social and economic relations between commoners and leaders. It is through these "social contracts" that leaders exact labor and resources from producers, while a portion of that surplus is then distributed as public goods and services that benefit larger cooperative endeavors. The more rulers depend directly on their immediate sustaining populations for their support, the more agency and voice that populace is likely to be able to assert, the more corporate/collective governance is apt to be, and the more public goods are likely to be dispersed. This dynamic may underlie the empirical co-occurrence of agricultural intensification features (terracing and irrigation) and monumental construction (public goods, such as roads, fortifications, temples, and meeting places), aptly noted by Earle and Spriggs but left unexplained (Blanton and Fargher 2008:254).

Alternatively, the monopolization or direct control of resources affords the powerful with greater opportunity to act in less collective, autocratic ways as they become less reliant on the exaction of labor or goods from their internal populace, and so they may afford them less voice. From my reading of the Earle and Spriggs account, this more autocratic practice of rule does not seem characteristic of the Pacific cases under study with the exception of the end of the Hawaiian sequence, when power was most highly centralized. What is important is that this transition and the resultant amassing of more concentrated power seems to be undergirded both by a greater reliance on military conquest and associated spoils (Kirch 2010) and by retinues of attached craftworkers, who produced status items that could be worn or handed out by rulers to procure allies and favor. From the standpoint of the collective action frame, key shifts in the fiscal underpinnings of power had implications not just for the hierarchical complexity of late Hawai'i's ruling authorities but for the nature of the dyadic relations between leaders and followers from more to less collective forms of governance.

Through their more explicit affording of nonelite agency, Earle and Spriggs have productively repositioned the political economy theoretical approach in archaeology. By so doing, they begin to address the micro-macro problem (Schelling 2006): that macroprocesses have bases in micromotives. Like Earle and Spriggs, I see the ties that link principals and followers as well as the fiscal processes that underpin the nature and practice of leadership as crucially important. But preindustrial power and the institutions of governance need not always rest squarely on direct economic control or own- ership of land, wealth, or property. The economic foundations of large networks of human cooperation were not always the consequence of political command, elite control, or centralized state ownership; rather, preindustrial economies were much more variable (Blanton 2013; Feinman and Garraty 2010; Smith 2004). The recognition of that diversity is critical to understand and explain history's alternative pathways in comparative terms.

\section{Maurice Godelier}

Ecole des Hautes Etudes en Sciences Sociales (EHESS), 190-198 avenue de France, Paris 75013, France (maurice.godelier@ehess.fr). 19 III 15

Earle and Spriggs's article is a plea to archeologists to adopt, or readopt, a Marxist approach in their discipline. The authors invoke Karl Marx and Gordon Childe but reassure us that they are not asking us to impose a priori schemas on historical facts envisaged over the long duration, that processes are "reversible," that there are always other paths, that there is not a necessary succession of "stages," that the rise of chiefdoms is not inevitable, and so on. The authors are therefore not seeking mechanically to link causes and effects, as was often the case between 1960 and 1980, when various versions of Marxism exerted a strong pull on the social sciences.

But what concepts do they propose for activating a refurbished Marxist approach? I see two: political economy and economic bottleneck, also termed constriction point. I will first take the concept of political economy, which they define as "an outcome of ecological, topographic, epidemiological, technological, structural, and other historical factors," a list of totally heterogeneous factors that, through their interrelations, "created the engine that resulted in wide variability in political forms." This definition fails to advance any hypothesis as to the relations of cause and effect that led certain of these factors, individually or together with others, to bring about new forms of political power. We are a long way from Marx, who defined political economy in a more restrictive fashion as the combination of social relations of production that position individuals and groups with respect to access to and control of the means of production (land, labor, etc.) as well as access to and control of the use and circulation of the products of labor - and the productive, intellectual (cognitive), and materials forces involved in the various labor processes - the production process unfolding each time within a definite ecological context.

It is therefore necessary to explain the different positions these individuals and groups occupy at a given time and in a given social structure in the production processes. This is where we must take a closer look at the notion of constriction point. As I understand it, those who possess power can, under certain circumstances, control and restrict the access of other members of their social group to land and other re- 
sources essential for the reproduction of the society (prestige goods, large fishing or war canoes, etc.). It is thus necessary to possess power to be able to create a bottleneck, and this power must place the other members of the society in a relationship of dependence, such that they are forced to accept that access to and use of the resources essential to the life of all are controlled and restricted by those who possess the power.

What powers in these societies and at these periods in time could have brought the constituent groups to depend on the individuals who exercised such powers? To my mind, it must have been in the first place powers arising from religious and ritual functions, because these powers were conceived and experienced as being beneficial for everyone. They held out the promise of good harvests, successful fishing, safe navigation, women's fertility, and so on. It was therefore in conjunction with such "immaterial" services that a set of obligations could have arisen with respect to those who exercised these functions. There was therefore no need at this stage to resort to force to create these obligations, which translated into countergifts, produce, labor, services, and so on. Yet it seems that the Austronesian groups that were to become the Polynesian peoples left their homelands in Taiwan and southern China with representations of the world that already contained the idea that some men were imbued with exceptional powers enabling them to communicate with the spirits and the gods, a mana of sorts, and that they could place these powers at the service of everyone. But these powers precede any transformation of economic relations, and these relations cannot explain the powers, either directly or indirectly.

Alternatively, the exercise of these powers can indeed transform economic relations. For if the countergift for the (immaterial) services provided by ritual specialists are produce, labor, services, and so on, that means that those who provide these countergifts must produce not only their own means of existence but also a surplus for those who exercise the political and religious functions. It is the appropriation and extension of this surplus that will become the strategic variable in the extension and transformation of the forms of power exercised. The surplus appropriated and transformed by those who hold these powers into their own material and social conditions of existence is thus the strategic variable that would explain the variability of political forms, taking into account the capacities of those who do not exercise these powers to resist growing pressure to "give" even more to those who do. This hypothesis concerning the conditions of extraction and expansion of a surplus used by a dominant minority for the purpose of their own social and material reproduction was central to the original Marxist theory, and the present authors have adopted and exploited it successfully, it seems to me, in comparing the three societies they have chosen.

A number of questions come to mind at this point, but I will choose only one: that of the rapid disappearance of the
Lapita civilization of the first settlers of these South Pacific islands. If the large potteries adorned with geometrical motifs and human figures were used in rituals and suggest that these populations had both ritual specialists and artists capable of making such vessels, what then does the disappearance of these ceramics mean? Did they disappear because the rites were abandoned and the social hierarchy they involved disappeared with them? Perhaps. But what would that mean in terms of history and anthropology? After this disappearance, societies would have found themselves more egalitarian than before but would still have the idea that some men possessed mana, that there was something divine about them. The process whereby a social hierarchy would be reborn that placed at the top of society those who exercised the religious functions, performed the rites, and claimed to ensure well-being and justice for everyone in exchange for their labor and their submission could only start over again. Earle and Spriggs show this clearly, which is another important point in their comparisons.

\section{Patrick V. Kirch}

Department of Anthropology, 232 Kroeber Hall, University of California, Berkeley, California 94720, USA (kirch@berkeley.edu). 26 I 15

I applaud Earle and Spriggs's effort to redeploy a Marxist approach to the interpretation of prehistoric change in the Pacific Islands. In spite of promising insights offered by Friedman (1981) and others, a Marxist approach has never been fully developed in the Pacific, as indeed the potential analytical power of Marx's theory of precapitalist social formations has been largely ignored by mainstream "processual" archaeology. Earle and Spriggs emphasize the identification of what they call bottlenecks in ancient Pacific political economies: "constriction points in commodity chains," which were targeted by chiefs or other individuals and manipulated for economic gain and/or power.

I restrict my comments here to the case of Hawai' $i$, to which I have devoted many years of research (Kirch 1985, 2010, 2012). While agreeing with much of what Earle and Spriggs write about Hawai i, I do not think they have taken a Marxist approach far enough. In particular, I am surprised that they do not fully explore the emergence in late precontact Hawai'i of true exogamous classes and therefore also of class struggle. After all, as they themselves quote Marx and Engels: "The history of all hitherto existing society is the history of class struggles" (2012 [1848]).

Their model of the transformation of Hawaiian society builds on Earle's earlier work (1997), which characterized Hawai' $i$ as a "staple economy" based on intensified agricultural production. Ruling elites took control of the bottleneck between the production and distribution of foodstuffs, channeling surpluses into their own storehouses to support 
"managers, warriors, and priests in the process of institutional reformulation." This is fine as far as it goes, but in my view (1) fails to give full recognition to the emergence of exogamous classes and (2) underestimates the extent to which a "prestige-goods" economy was grafted onto the underlying staple economy in the past 2 centuries prior to European contact.

Across the breadth of Polynesia, only Hawai'i (and probably also Tonga) saw the emergence of true exogamous classes out of an older, ancestral Polynesian social structure of ramifying descent groups. By the time of European contact in Hawai' $i$, these classes - na $\bar{a} l i c i$, the chiefs, and nā kanaka, the commoners-constituted what Marshall Sahlins described as a "genuine political society" (1999:23). The social relations of production as well as the control over the means of production (to invoke those key Marxian analytical categories) had been profoundly restructured. Nā líi did more than just extract surplus at the bottleneck, they took absolute control of land - the very means of production. This change, from land being controlled by descent groups to one in which chiefs held territories and commoners paid obligatory tribute (tax) in exchange for the right to work the land, could not have been more fundamental, setting up precisely the conditions for class struggle that Marx predicted.

Earle and Spriggs's simple remark that the agency of Hawaiian commoners should "never be discounted" does not do justice to the potential for a true Marxian analysis of class struggle in Hawai'i. Native Hawaiian historian David Malo wrote that "many kings have been put to death by the people because of their oppression of the makaainana [commoners]" (1951:195). Kirch and Sahlins (1992) documented abundant examples of commoner resistance to excessive nā líi $i$ demands in their study of O'ahu's Anahulu Valley (such as the mixing of goat dung into taro paste destined for the household of the high chiefess). Although these examples derive from the immediate postcontact period, they almost certainly reflect the continuance of class struggles that began in precontact times.

Although Earle and Spriggs recognize that "prestige goods were an essential part of the Hawaiian political economy," they seem reluctant to pursue this further, opining that the "model of a prestige-goods economy" is not applicable to Hawai'i. I beg to differ. While it is certainly the case that in its earlier stages of development the Hawaiian political economy was based on the intensification of agricultural production (in both irrigated and dryland zones), substantial evidence supports the argument that as the size and power of the chiefly class expanded dramatically after AD 1600, a significant prestige-goods economy began to be grafted onto the base staple economy. These prestige goods included first and foremost the elaborate featherwork (capes, cloaks, helmets, etc.) but also all kinds of other craft goods (ranging from wooden bowls, fine mats, and barkcloth to war canoes) manufactured by specialists residing in the royal centers. I would argue that by the time of European contact it was the control and distribution of such sumptuary items that preoccupied the chiefs, far more than control over food production, which they happily delegated to their land managers (konohiki). And, following European contact, this emphasis on prestige goods led directly to a "political economy of grandeur" (Sahlins 1990), based on the competitive importation of European goods.

\section{Dean Saitta}

Department of Anthropology, University of Denver, Sturm Hall 146-S, 2000 East Asbury Street, Denver, Colorado 80208, USA (dean.saitta@du.edu).26 I 15

The great virtue of the archaeological record is its potential to illuminate alternative ways of organizing social life of which we have no direct experience. For some of us, the Marxist tradition of political economy is very helpful in drawing out this variation. Marx is getting lots of attention today given deepening social inequality worldwide. But he has always been relevant for scholars interested in understanding the different ways that humans mobilize social (surplus) production. Marxian concepts capture causal powers that other approaches do not. Among other things, they allow us to see variation around basic themes where other approaches see distinct evolutionary types or stages. Thus, I completely agree with Earle and Spriggs that now is a good time to renew our engagement with Marxist theory as a means to explain organizational variation in past societies and, especially, longterm change.

As the authors note, scholars like Jonathan Friedman were instrumental in developing a Marxist approach for archaeology. Friedman's signature accomplishment was bringing Marx and Levi Strauss together to show how kin relationships can be used to generate social inequality and class exploitation. Even Ian Hodder's postmodernism played a useful role in this project. Rather than rejecting materialism, Hodder helped to enrich it by elaborating the interpretive anthropologist's fundamental insight that meaning is public and thus inherently material. By helping to create and reproduce systems of meaning, material culture is instrumental in sustaining the politics and ideologies that support particular ways of mobilizing social surplus. It is also instrumental in challenging them. Finally, Eric Wolf's particular integration of the material and the ideal in a broadly Marxist approach was crucial for turning archaeology in some fruitful theoretical directions for understanding social variation and change.

Earle and Spriggs convincingly demonstrate different pathways to power in Pacific social formations that cover the spectrum from egalitarian to stratified. However, it is not always clear what surplus mobilization means in their approach. For Marx, the mobilization of surplus in any kind of social formation involves a class relationship. He distin- 
guished between fundamental classes that produce and extract surplus and subsumed classes that distribute and receive shares of extracted surplus in return for providing the various economic, political, and cultural conditions that allow fundamental class relations to exist. Marx theorized his fundamental class relations as primitive communal, feudal, and capitalist, among others. In so doing, he allowed that power, property, and class are different relationships that can combine and reinforce each other in variable and complex ways. In Marx's world, it was possible for communal relations of surplus production to coexist with chiefly hierarchies and even state bureaucracies if those holding power helped to reproduce the conditions that allow communal appropriation to proceed. In other words, political domination is not necessarily congruent with economic (class) exploitation.

Variation in the form and conditions of communal class relationships - where society as a whole is the presupposition for surplus appropriation and distribution - is the convergent quality that I am inclined to see characterizing the authors' spectrum of egalitarian to stratified societies in the Pacific. In their most socially complex cases, the authors refer to "exploitation," "rent," and "feudal-like" relationships. These concepts imply the existence of a class division between producers and appropriators of surplus, that is, a tributary class relationship. However, it seems just as reasonable to conceptualize the various specialists involved in land management, warfare, and religious sanctification as communal subsumed classes supported by collectively mobilized surpluses. The same goes for the skilled artisans who manufacture symbolic objects in exchange for land or support within elite households. The authors emphasize that political systems across the Pacific's spectrum of variation were always unstable, difficult to maintain, and constantly negotiated. They consistently mention the limits of elite power and emphasize that primary producers always had agency. Commoners were never simple pawns in these relationships and could always challenge hierarchy and vote with their feet "when exploitation became extreme."

In short, Earle and Spriggs's analysis suggests that throughout the prehistoric Pacific we have political variation that is consistent with fundamentally kin-communal class relations of surplus extraction and distribution, that is, a kin-communal mode of production. Rather than suggesting changes or transformations in political economy, the archaeological record is documenting the tenacity of kincommunal class relationships in a context where exploitative class relations are always threatening to break out (and may have, from time to time). If so, then what Earle and Spriggs theorize and empirically substantiate is interesting and valuable. I am not sure that their approach will suggest concrete ways to reduce contemporary social inequalities. However, their analysis might prompt more and better critical reflection about how the past is different from the present. It could even show us how fundamentally nonexploitative relations of surplus appropriation can take a multiplicity of complex forms, some of which might have relevance for insurgent and transformational social movements today.

\section{Peter Sheppard}

School of Social Sciences, University of Auckland, Auckland 1010, New Zealand (p.sheppard@auckland.ac.nz). 25 I 15

Processual archaeology was strongly influenced by the work of Sahlins, particularly his 1963 article "Poor Man, Rich Man, Big-Man, Chief." I am not certain, however, how many read it closely. Sahlins cautions in a footnote that these types are generalizations and that there was a great deal of social complexity in Melanesia. His big-man model was influenced by the work of Douglas Oliver on Bougainville (Oliver 1955), and his caution may have come in part from Oliver's recognition of a cline of social complexity in south Bougainville (Oliver 1956; Thurnwald 1934). In a later paper, Oliver (1971) noted that "from northwest to southeast, a clearly marked range in emphasis from maternal to paternal ties and descent is paralleled by a shift in the basis of status hierarchy, from kinship and age (north-west) to stress on renown and a system of inherited class-status." Oliver proposed a number of factors, including ecological variation, population density, and ease of communication, to explain this variation but also noted the importance of influence from Austronesian neighbors who may have provided the "reference model" for status differentiation (Oliver 1971:286). A core symbolic structure grounded in the concepts of mana and tapu is found throughout the Austronesian societies of the Pacific. In the Solomons, such concepts can serve as the building blocks underpinning elaborations of political economy, such as the large chiefdom of Roviana in New Georgia where chiefs, commoners, and slaves lived in dense communities and created a predatory chiefdom that dominated much of the western Solomons. In simple economic terms, this was founded not on intensification or appropriation of surplus but on cultural manipulation of a distributed regional economy (Aswani and Sheppard 2003; Sheppard and Walter 2013). But symbolic structure is not by itself a sufficient explanation for variation in the Solomons, just as it was not for Oliver, for whom resource variation and communication were important. But is that alone sufficient to explain the apparent East Polynesian/Island Melanesian divide? For another Melanesian anthropologist, Roger Keesing, there had to be some major cultural change to account for the difference.

The evidence points toward the processes whereby hereditary chiefs become transmuted into an aristocratic class in Polynesia (and some parts of Micronesia) as a key to the emergence of the metaphysic of mana. It seems not simply to have been the increasingly godlike status of the highest chiefs that progressively led to the sanctification of their 
persons (to which mana and tapu in their most fully developed forms give expression). I believe that the creation of developed theologies among Oceanic speakers reflects the emergence of a class of theologians, out of the older Polynesian custodians of lore, ritual, magic and genealogical knowledge. Theologians as part of the chief's entourage, celebrating and rationalizing the chief's sanctity, seems to have elaborated the cosmological implications of mana into metaphoric "power." (Keesing 1984:152)

There are differences between Island Melanesia (Lapita Land) and Polynesia-signaled most simply by the great linguistic diversity of Melanesia versus the one language, one archipelago model of Polynesia - which I suspect are not simply the result of variation in resource access, bottlenecks, or malaria. Malaria is endemic to the Solomons and today is found south into northern Vanuatu, although in the past it may have been of more limited distribution beyond Near Oceania (Sheppard 2011). Archaeology indicates that populations in the western Solomons were, despite malaria, much higher in the past and possibly as high as that on the very populous island of Malaita today. And, of course, malaria is endemic to many areas where states, complex chiefdoms, and kingdoms were found in Southeast Asia and Africa (Blanton and Fargher 2008).

Agency is noted as a mechanism of resistance in this paper; however, perhaps the biggest assumption of agency is the desire by individuals to accumulate power through control of resources. This seems like a version of the aggrandiser hypothesis (Hayden 2001). One of Marx's most powerful concepts is relations of production, which ultimately constrain the development of the means of production. Agency of individuals, including leaders, is constrained by the relations of production. The rights to land and its productive capacity in the Solomons is based on genealogy, and although chiefs can adjudicate disputes based on control of knowledge, their ability to alienate land or production is limited and in a constant state of political tension. The modern state of the Solomon Islands has great difficulty in acquiring customary land. The fundamental rupture of relations of production whereby chiefs come to own or control land rights seems to have rarely happened in the Pacific. Perhaps such ruptures are signaled, as suggested by Keesing, by the development of a class of theologians who naturalize the control of production by godlike chiefs or kings.

Michael E. Smith

School of Human Evolution and Social Change, Arizona State University, Tempe, Arizona 85287, USA (mesmith9@asu.edu). 24 I 15

As a materialist who works within a political economy framework, I find little that is objectionable in this generalized de- scription of change on selected Pacific islands. It is an untested just-so story, and I look forward to a lengthier and more formal account in the future. Two things about this paper puzzle me. First, why is the approach labeled Marxist? And second, why are some of the most productive and insightful theoretical approaches of contemporary materialist research ignored?

Earle and Spriggs note in passing that "much of the US processual tradition is generally grounded in Marxism," an observation that is widely accepted (Trigger 2006). Evolutionary scholars such as Steward and White were hesitant to acknowledge the Marxist influence on their theories. By the end of the Cold War, as Service, Harris, and others were solidifying the neoevolutionary approach in US anthropology and archaeology, the Marxist element in their work had become embedded and implicit. Few neoevolutionary scholars (such as Earle) gave much lip service to the writings of Marx or referred to their work as Marxist. Yet it is easy to trace the development of their theories back to Marx.

By now, the pervasive influence of Marx's ideas on neoevolutionary and other materialist approaches in archaeology is of interest primarily to historians of archaeology and self-identifying Marxist scholars. The latter cite the works of Marx frequently and continue to employ his concepts in a direct manner today (e.g., McGuire 2008a; Wurst and Mrozowski 2014). There is a resurgence of interest in Marx (Eagleton 2011), to the point that even nonmaterialist interpretivist archaeologist cite him (e.g., Swenson 2014). But if most materialist archaeologists today do not see the need to cite Marx directly, why do Earle and Spriggs label their account Marxist?

I have a small historical quibble with Earle and Spriggs's comments on Ian Hodder and the rapid ascendance of postprocessual and antimaterialist ideas in archaeology. They suggest that one reason for the growth of this movement was the fragmented nature of historical materialism in the 1970s. Perhaps. But a more important driver may have been the fact that Binford and the New Archaeologists hitched their approach to a discredited and unworkable epistemological bandwagon: the logical positivism of Hempel and others. Coveringlaw explanations simply do not work in the social sciences (Bunge 2004; Tilly 2008), a notion that was already clear to philosophers of social science by Binford's time (Morgan 1973). To me, it looks like materialist accounts in archaeology took a back seat to idealist and interpretivist accounts in large part because the materialists were unable to articulate a workable epistemology, leaving their explanations in doubt.

My second puzzle with this paper is why large bodies of useful explanatory theory from materialist, or political economy, approaches are ignored. Much of this work originates in other disciplines, and archaeologists are now starting to explore its implications (Blanton and Fargher 2008; Carballo 2013). Perhaps because US archaeology developed historically within departments of anthropology, most social theorizing has been limited to ideas from anthropology and archaeology. My doctoral training in the late 1970s taught that fields like 
sociology and political science were irrelevant because their ideas about modern society are just not applicable to ancient societies. After I broke out of this straightjacket less than a decade ago, my own research and understanding of ancient cities and states flourished (Smith 2011).

Elsewhere (Smith 2012), I take Patrick Kirch (2010) to task for labeling the Hawaiian polities as states (I think he is correct) yet refusing to analyze them with the full social science toolkit available for the study of state societies. Regardless of how Earle and Spriggs choose to categorize the societies they describe, their analysis would be much improved if they expanded their conceptual horizons this way. Here are just two brief examples. Their discussion of commoner agency would benefit greatly from the insights of collection action theory (e.g., Blanton and Fargher 2008), particularly Margaret Levi's (1988) concept of quasi-voluntary compliance. Second, the concepts of wealth and staple finance - very useful when first articulated (D'Altroy and Earle 1985) — are now clearly inadequate to model early fiscal organization, even in nonstate polities (Kiser and Kane 2007; Monson and Scheidel 2015; Smith 2004).

My concern with the authors' use of the term "Marxist" pertains primarily to the history of archaeology, but my concern with their limited conceptual approach identifies a larger intellectual problem in contemporary archaeology. We have been blinded by our strict adherence to the models and theories of anthropology, and we need to incorporate more vigorously insights and concepts from the other social sciences. Otherwise, our understanding of past societies and their transformations will remain parochial and moribund.

\section{Jim Specht}

Geosciences and Archaeology, Australian Museum, 6 College Street, Sydney, New South Wales 2010, Australia; and School of Philosophical and Historical Inquiry, University of Sydney, Australia (jspecht@bigpond.com). 23 I 15

Earle and Spriggs's attempt to provide a coherent, overarching theoretical framework is stimulating, but the paper is overly ambitious, and many issues are oversimplified or ignored. This partly reflects differences in the quantity and quality of data for the three case studies, of which the Hawaiian one is the most convincing. The studies have vastly different timescales: 300-400 years for Lapita, around 1,000 years for Hawai $i$, and 2,000 years for Vanuatu. Do these differences have a distorting influence on perceptions and interpretations of emergence and development of chiefdoms?

Central to the argument are "economic bottlenecks (constriction points) based on property rights in land or on production and trade in prestige goods," "commodity chains" of various kinds, and "control points" over resources for chiefs and pretenders. Bottlenecks are defined as "unintended consequences of environmental conditions" or "intended con- sequences of strategic actions." The problem is to identify which factor operated in a particular situation; if there is no case for environmental conditions, does that automatically mean strategic action was the agency?

The environmental conditions likely to have influenced social development in the Hawaiian and Vanuatu studies are clearly stated, but the topic is inadequately discussed for the section on the Lapita cultural complex. To restrict description of the environmental contexts of Lapita sites to "small populations... located along the beaches on little and large islands" is reductionist to a fault and fails to acknowledge the diverse range of contexts of these sites: in the shadow of active volcanoes, on atolls or uplifted reef islands, and on islands with complex geology. These islands differ in productivity potential, yet the authors skim over the differences and present the Lapita cultural complex as a uniform entity across thousands of kilometers of islands and ocean. The Lapita cultural complex was not uniform; significant differences exist between sites (Green 1992), but why? Was it due to environmental factors, the result of strategic choices, or both? Does the blanket term "Lapita" embrace the material remains of multiple ethnolinguistic communities (cf. Pawley 2003) and not a set of closely related communities speaking a single Proto-Oceanic language, as is claimed?

For prestige and wealth goods, the authors acknowledge the problem of the "ever-present missing record" (Green and Kirch 1997): items of organic material culture that do not survive in the archaeological record, or only rarely so (cf. New Zealand; Irwin 2004). The list of such items is extensive in the New Guinea region in recent times (Harding 1994), where they played substantial roles in diverse economic and social relationships. With the mats and feathers discussed in the paper, their absence from the archaeological record presents challenges for interpreting past political economies, just as relying on inorganic goods would be at best incomplete and misleading.

The authors omit reference to the work of Torrence and her colleagues on pre-Lapita obsidian stemmed tools in Papua New Guinea (see references in Torrence, Kelloway, and White 2013). Production of the finest tools required complex skills and plenty of raw material and occurred in the Kutau/Bao and Mopir obsidian source areas of New Britain. Given the significance of New Britain obsidian, some form of access control must have operated, as in the recent past (Specht 1981). This would have created bottlenecks, and the dominance of Kutau/Bao obsidian in Lapita sites arguably reflects this. With the restriction of access to Mopir following the W-K2 eruption (Summerhayes et al. 1998), Kutau/Bao became the New Britain source of choice. The authors dismiss the obsidian in Lapita sites as potential prestige items but miss the point. Value and prestige were not necessarily inherent in the obsidian per se or in the items made from it but were inherent in the capacity of individuals to acquire it from a great distance and then distribute and use it uneconomically (Specht 2002, pace Sheppard 1993). 
The paper does not discuss the Bismarck archipelago before Lapita pottery, yet some form of social differentiation appears to have existed in some parts (Torrence, Kelloway, and White 2013; Torrence and Swadling 2008; Torrence, White, and Kononenko 2013). Were the simple chiefdoms of Lapita introduced along with pottery, did they owe something to the prior conditions in the archipelago, or did they develop independently? Not all Lapita settlements were necessarily occupied by simple chiefdoms, but whether the diverse leadership systems of recent times (Roscoe 2000) existed or began at that time is unknown. These questions open a rich field for future research, and the challenge is to develop strategies to address them.

Despite my negative tone, I believe Earle and Spriggs have produced a potentially fruitful way forward, especially for the western Pacific Islands, where scant attention has been paid to issues of political economy. But we must guard against assuming that their interpretations are demonstrated. As the authors state, much more targeted work is needed.

Tim Thomas

Department of Anthropology and Archaeology, University of Otago, PO Box 56, Dunedin 9054, New Zealand (tim.thomas @otago.ac.nz). 27 I 15

This paper presents a welcome call to retain an examination of the conditions of social inequality at the center of our accounts of prehistoric Pacific societies. As noted in the conclusion, historical materialism lends itself to grand narratives, although Earle and Spriggs disavow inevitability and unilineality. A comparative scientific endeavour that identifies recurring mechanisms such as bottlenecks must be claiming some level of predictability, however, no matter how complex the reality. The cross-cultural impetus toward stratification in their account is provided by Machiavellian individuals who take advantage of the affordances of the productive environment to control the distribution of staple foods and/or other items of value. The authors are most comfortable explaining how this works when control focuses on food production, especially surplus-producing garden systems. The explanation works particularly well for Hawai $i$, where the archaeological sequence is well understood and social organization approached the state-level forms for which Marxist and related critiques of political economy were developed and arguably remain best suited.

The Melanesian cases are more problematic and explained mostly by way of comparison, whereby a relative absence of the conditions of opportunity commonly exploited in chiefdoms explains the relative lack of stratification (or, as in the Lapita case, is used to argue for a lack of stratification). The archaeological sequences are less complete, and so developing accounts of the internal workings of these political economies may be difficult without a constituting other. But the method of evaluating bottlenecks itself means that the authors are not quite able to describe "how dominant control was effectively resisted to create more decentralized structures"-instead, we mostly get an account of how dominant control was unable to be effectively pursued.

There is also the question of whether Melanesian social forms rest on premises about persons, things, and their relations amenable to Marxist analysis. Since the 1980s, neoMaussian ethnographies of Melanesian gift economies have questioned the applicability of concepts of property, alienation, and individuality to political economies in the region, exemplified by Strathern's (1988) critique of gender exploitation in Papua New Guinea. A Marxist rejoinder might be that such critiques identify mystifications that are largely irrelevant, since the material outcome is the same-products are appropriated, power inequalities emerge (see Graeber 2001:41). Nevertheless, there is a potential blind spot to the influence of foundational concepts, categories, and ontologies in materialist approaches that do not grapple with these differences.

Take, for example, the role accorded here to inherited political structures in colonizing populations - the authors "de-emphasize ... founding structural principles" in favor of the postulation that inequity was suspended on newly settled islands only to emerge anew given the right conditions. The archaeological evidence for imported hierarchies in colonization-phase sites may be equivocal, but comparative studies of social organization, leadership terms, and resource governance across Polynesia strongly suggest that the people there followed a common set of cultural principles in political life as populations grew (Kirch and Green 2001). The radially segmented clan territories of several Polynesian high islands (e.g., ahupua'a, tapere) may be seen as a cultural form that structured power relations - ensuring in-group selfsufficiency (Kirch 1984:33) - and was a model that could be scaled up to integrate people and territory. A contrast is provided by Melanesian islands with opposing inland and coastal landholding groups that engaged in reciprocal exchange to access a full range of resources. The irrigated taro systems of New Georgia did not facilitate the emergence of regionally integrated chiefdoms, remaining reciprocally dependent on exchange with coastal communities, and in late prehistory were abandoned in favor of a coastally dominant political economy focused on shell valuables and symbolic headhunting expeditions (Sheppard, Walter, and Nagaoka 2000; Thomas 2009). The Melanesian ideal of reciprocity is also seen in the reputation of Roi Mata as a chief who achieved peace via a legendary feast - warring parties brought different food items that subsequently became their clan symbols or totems in the naflak system (Luders 2001:256). According to local conception, then, integration was achieved not with specialized warriors but through balanced reciprocity in a system of settled differences. Violence in many Melanesian societies was deployed as a tool to delimit social groups (Harrison 1993) rather than enforce integration. Gift exchange is so effective at entangling people 
that the problem becomes how to create boundaries or cut the network (Strathern 1996). In New Georgia, where gift exchange made resource redistribution between allied tribes appear as a form of familial sharing, chiefs conducted headhunting raids that simultaneously demonstrated the mana (efficacy) of their lineages while setting limits to affiliation. Surrounding territories were depopulated rather than expanded into. Political power emerged under cultural conditions that resisted alienation.

In drawing attention to the role played by prevailing conceptual schemes I do not mean to suggest that these are more influential than factors like environmental biodiversity or epidemiological population limits in shaping political organization. But we do need methods that can detect these sorts of differences in the archaeological record; otherwise, we risk portraying alternative political structures as more or less impoverished versions of states.

\section{Reply}

The depth, thoughtfulness, care, and creativity of the comments to our article are greatly appreciated. All contribute to the further development of theory and explanation in Pacific archaeology and beyond. They equally support a sciencebased, comparative approach to archaeological sequences of sociocultural change. This agreement is important; it argues strongly that archaeology can now look systematically at processes of social evolution after the recent deflation of the postprocessual balloon. As the commentators suggest, research by an eclectic (and for want of a better word) processual archaeology can finally bury the straw man of unilinear, stage-based formulations previously constructed solely with ethnographic cases. As noted by Feinman, the rapidly improving archaeological record creates a rich opportunity to fashion a theory-driven understanding of social evolution. Such a comparative approach to the longue durée can be one of anthropology's signature pillars supporting a sciencebased understanding of the human experience. Only archaeologists can do this. We envision anthropological archaeology as a robust, historical science studying common processes with specific evolutionary sequences.

Fargher correctly argues that "a scientific approach would entail using archaeological data ... to systematically test Marxist predictions." Then, rather disingenuously, he says that we "accept... [Marxist] assumptions and assertions unquestioningly." His statement misrepresents our article, which we see as the critical research step of model construction based on existing data that were often collected for purposes of culture history. Our hypothetical model — what Smith calls a just-so story - is not meant as a statement of purported facts; rather, it serves analytically to shape a research agenda by pinpointing key parameters requiring future archaeological research. It is an attempt to kick-start innovative discussion in a Pacific archaeology field that has perhaps become rather stultified of late in its theoretical development. Effective research must be guided by theory so as to identify key data, such as those related to bottlenecks, that are required to test and improve the model's applicability. Constructing a shared intellectual approach also allows for data collection that can be more easily compared.

Should we call our approach Marxist? Although recognizing that neoevolutionary anthropologists (Fried, Harris, Steward, White, Wolf, etc.) and anthropological archaeologists (Binford, Childe, Earle, Feinman, Flannery, etc.) easily trace theoretically to Marx, Smith asks pointedly, "But if most materialist archaeologists today do not see the need to cite Marx directly, why do Earle and Spriggs label their account Marxist?" Fargher would seem to see Marxism as misguided, reminding us of the blind "un-American" view of Marxist theory once broadly held by US society. Dismissing Marxism is a mistake, and we hold to the label for two reasons. First, we want to correct the history of the American neoevolutionary tradition, which for political reasons obscured its Marxist foundations. Second, equivalent to biology's foundational dependence on Darwin's insights, we want to encourage a new materialist synthesis that helps to integrate anthropological materialism as a common endeavor with collective roots, for which Marx was the intellectual leader, just as Darwin provided the intellectual foundation for modern biological evolution.

A premise of our article is that materialist approaches share common principles that make them complementary (not competitive) with each other. We believe that most "different" approaches to social evolution actually address complementary aspects of the overall topic. Our approach to power and political control should be fairly clear from the article; we never imply that it is comprehensive. Central control, for example, was never easy or unproblematic; it was always contested and exercised within existing social formations. To varying degrees, as well clarified by several commentators, a balance of bottom-up and top-down dynamics characterizes traditional societies. Saitta (1997) describes how "collective action" works in the "subsumed" class systems of traditional societies as a means to generate surpluses to support the political structure. He emphasizes that resource extraction and distribution existed through much of the Pacific as "a kincommunal mode of production." Thomas provides information that supports this point by emphasizing that our analysis of Lapita and Melanesian societies shows that potential bottlenecks were not easily controlled. Absolutely. He points out that Melanesian scholars emphasize that this region had fundamentally different conceptions of such things as property, alienation, and individuality, and he describes a Melanesian pattern of reciprocity that provides a structural alter- 
native to Polynesian redistribution. Following up on Saitta, we emphasize that the apparent differences (too simply glossed as Melanesia vs. Polynesia) may be more quantitative than qualitative and that any model of structural division should be tested by archaeological studies of the sequences. As Thomas suggests, apparent qualitative differences may obscure similarities in political process.

Kirch provides a useful expansion of our argument that should be carefully considered. He believes that we do not take "a Marxist approach far enough... [because we] do not fully explore the emergence in late precontact Hawai'i of true exogamous classes and therefore also of class struggle." $\mathrm{He}$ provides a brief synopsis of his extensive work on this topic that we embrace. In a close reading of his publications, we sense that he emphasizes structural transformation more than the driving forces of political economy, but our differences are only in emphasis.

Godelier has been a major influence on our intellectual development, and we welcome his substantial comment to our article. He raises the question of whether our definition of political economy includes "a list of totally heterogeneous factors" that makes it distant from Marx's elegant definition. We feel, however, that to apply Marxist concepts broadly we must expand the totality of economic conditions to include explicitly environmental and social factors. These factors are all implicit in Marx's analysis, but his work was tailored to an industrial economy, for which these factors were arguably less significant. Our cause-and-effect relationship is based on the nature of bottlenecks - how potential constriction points in economic systems determine the nature of power and structural control.

Godelier emphasizes the value of our approach by his consideration of the structural role played by religious leaders as an original source of power in traditional societies. He sees religious powers as preceding economic powers and providing the immaterial services that allow for the transformations of economic relations. As elaboration for the kincommunal means of production discussed by Saitta, Godelier extends the theoretical reach of our analysis into the realm of traditional societies, where bottlenecks were nonexistent or weak. This extension fits well with our understanding of how chiefs in Vanuatu were able to elaborate ceremonial cycles and monument construction to assert some control over staple production. Monument construction in low-density societies, such as the European Neolithic or the American Woodland, suggests a possible religious basis for the political economy and its social differentiation (M. Artursson, T. Earle, and J. Brown, unpublished manuscript). This early emergence of religious power, as seen in the archaeological record, supports Godelier's argument.

In his discussion of Melanesian political systems, Sheppard refers to the foundational thinking of Oliver, Sahlins, and Roger Keesing - all ethnographers who by chance were professors of Earle at Harvard and Michigan and who influenced his early intellectual formation. Oliver, for example, recognized a cline in social complexity across Bougainville, which is exactly the type of variation that archaeology can investigate with a political economy approach. Sheppard further discusses Keesing's creative emphasis on the role played by theology in Oceania that resulted in a "class of theologians," who could have been leaders in their own right or power specialists for chiefs.

Ideology can be a strong source of chiefly power when it is materialized in forms that require production within a controllable political economy (DeMarrais, Castillo, and Earle 1996). The relative roles of the three elemental sources of power (economic, military, and ideological) have distinct and variable significance for the emergence of social complexity, but they are fundamentally linked to dynamics of the political economy (Earle 1997). We are intrigued by the ways that both Smith and Saitta contend that our admittedly rather cavalier dismissal of Hodder is unfair. It is true that Hodder's views have changed considerably over the past 30 years, and it was particularly the initial stages of his postprocessual journey that we were highlighting. As discussed in his recent book, Hodder (2012) now emphasizes how material culture is a public phenomenon that can be understood from a political economy perspective. Saitta clarifies, "By helping to create and reproduce systems of meaning, material culture is instrumental in sustaining the politics and ideologies that support particular ways of mobilizing social surplus. It is also instrumental in challenging them." Exactly. As materialized in things and constructions, ideology provides means of both control and resistance, depending on the particular place of the objects within the production process of the political economy.

We are encouraged by how the commentators bring theoretical perspectives and dynamics that would not easily be identified as Marxist to complement our approach. According to Smith, "we need to incorporate more vigorously insights and concepts from the other social sciences" in addition to anthropology. Yes, among the best examples are those from the Blanton group, who make explicit use of theoretical arguments drawn from political science. We agree with Feinman that "the economic foundations of large networks of human cooperation were not always the consequence of political command, elite control, or centralized state ownership; rather, preindustrial economies were much more variable." The foundational presentation for their position is Blanton et al. (1996), where the distinction is drawn between corporate and network strategies. Using political science research, Blanton and Fargher (2008) argue that many traditional states depend on corporate strategies. Where finance is internally based (as, e.g., in taxes on land), leaders provided apparent services to their subject population. In premodern states characterized by "collective action," commoners were able to retain a high degree of self-organizing control over their lives and require the elite to provide useful services 
to them. We see the apparent lack of control as a probable outcome of the particular political economies involved; to the degree that leaders depend on commoners for resources and labor, the commoners' bargaining position remained strong. As presented clearly by Feinman, "the fiscal foundations of governance often are... grounded... through a suite of reciprocal social and economic relations between commoners and leaders." That is the case even with true class systems in place.

One theme that we touch on briefly is that archaeology's concern with the longue durée should be relevant to understanding future possibilities for social change. Smith suggests that this will be possible only if we engage closely with nonanthropological theory, just as Blanton and Fargher's work does so effectively. Although such borrowings definitely enrich our discipline, we feel that reciprocally other disciplines can now gain substantially from archaeological approaches. For example, How Chiefs Come to Power (Earle 1997) has been quite broadly read and used by political scientists (see, e.g., Winters 2011). As a historical science studying topics of grea general relevance to the social sciences, archaeology can and should impact broader understandings of and designs for social change.

Various commentators suggest ways to apply a political economy approach that we have not fully explored. Perhaps most salient are those by the Oceanic archaeologists (Kirch, Specht, Sheppard, and Thomas), who emphasize the importance of historical details of potential significance to particular trajectories of regional developments. These points are well taken; social evolution is a historical science that must consider such important details in terms of how systems change, and we make no claim that our model is all inclusive of relevant evidence. Our model is a point of departure for future research; we never intended that it should close discussion but rather that it should renew discussion. Specht draws attention to the potential for additional bottlenecks in the Lapita cultural complex, which as yet may be unrec ognized as control points. He also draws attention to Torrence's work on pre-Lapita society lithic production and trade. The specialized, high-quality production that she documents suggests a potential local bottleneck that could have been responsible for some emergent social differentiation. Kirch discusses the role played by prestige-goods exchange in the later part of the Hawaiian sequence, which certainly deserves furthe: consideration.

As we read through the comments, our only regret is tha we did not receive more of them. We strongly recommend reading each comment with great care, as they offer important insights, only some of which we have had space to dis. cuss. We conclude that the overlaps of interests and concerns represented by such a growing cadre of science-based researchers are quite evident here. Our research naturally diverges, contests, and complements, but what we share in common provides a strong foundation. We carry different research agendas and scales of analysis, but together we can build a new synthesis of social evolution based on compara- tive studies of archaeological sequences (Neitzel and Earle 2014).

\section{— Timothy Earle and Matthew Spriggs}

\section{References Cited}

Adams, R. McC. 1966. The evolution of urban society. Chicago: Aldine. Aswani, S., and P. Sheppard. 2003. The archaeology and ethnohistory of exchange in precolonial and colonial Roviana: gifts, commodities and inalienable possessions. Current Anthropology 44(suppl.):S51-S78. [PS]

Bayliss-Smith, T., and E. Hviding. 2012. Irrigated taro, malaria and the expansion of chiefdoms: Ruta in New Georgia, Solomon Islands. In Irrigated taro (Colocasia esculenta) in the Indo-Pacific: biological, social and historical perspectives. M. Spriggs, D. Addison, and P. J. Matthews, eds. Senri Ethnological Studies 78. Pp. 219-254. Osaka: National Museum of Ethnology.

. 2014. Taro terraces, chiefdoms and malaria: explaining landesque capital transformations in Solomon Islands. In Landesque capital. N. T. Håkansson and M. Widgren, eds. Pp. 75-97. Walnut Creek, CA: Left Coast.

Bayman, J., and T. Dye. 2013. Hawaii's past in a world of Pacific islands. Washington, DC: Society for American Archeology.

Beck, R. 2003. Consolidation and hierarchy: chiefdom variability in the Mississippian Southeast. American Antiquity 68:641-661.

$\rightarrow$ Bedford, S. 2006a. The Pacific's earliest painted pottery: an added layer of intrigue to the Lapita debate and beyond. Antiquity 80:544-557.

. 2006b. Pieces of the Vanuatu puzzle: archaeology of the north, south, and centre. Canberra: Pandanus.

Bedford, S., M. Spriggs, H. Buckley, F. Valentin, R. Regenvanu, and M. Abong. 2010. Un cimetière de premier peuplement: le site de Teouma, sud d'Efate, Vanuatu [A cemetery of first settlement: Teouma, South Efate, Vanuatu]. In Lapita: ancetres oceaniens [Lapita: oceanic ancestors]. C. Sand and S. Bedford, eds. Pp. 140-161. Paris: Musee de Quai Branly/ Somogy.

Bell, D. 2004. Wealth and power. Walnut Grove, CA: Altamira.

Best, S. 2002. Lapita: a view from the east. NZAA Monograph 24. Auckland: New Zealand Archaeological Association.

Blanton, R. E. 2013. Cooperation and moral economy of the marketplace. In Merchants, markets, and exchange in the Pre-Columbian world. K. G. Hirth and J. Pillsbury, eds. Pp. 23-48. Washington, DC: Dumbarton Oaks Research Library and Collection.

Blanton, R. E., and L. F. Fargher. 2008. Collective action in the formation of pre-modern states. New York: Springer.

Blanton, R. E., G. M. Feinman, S. A. Kowalewski, and L. M. Nicholas. 1999. Ancient Oaxaca. New York: Cambridge University Press. [LFF]

Blanton, R. E., G. M. Feinman, S. A. Kowalewski, and P. Peregrine. 1996. A dual-processual theory for the evolution of Mesoamerican civilization. Current Anthropology 37:1-14.

Blanton, R. E., S. A. Kowalewski, G. M. Feinman, and L. Finsten. 1981. Ancient Mesoamerica: a comparison of change in three regions. New York: Cambridge University Press.

Bowles, S., E. A. Smith, and M. B. Mulder. 2010. Intergenerational wealth transmission and inequality in premodern societies. Current Anthropology 51(1):7-126.

Brumfiel, E. 1992. Breaking and entering the ecosystem: gender, class, and faction steal the show. American Anthropologist 94:551-567.

$\rightarrow$ Brunton, R. 1975. Why do the Trobriands have chiefs? Man 10:544-558.

Bunge, Mario. 2004. How does it work? the search for explanatory mechanisms. Philosophy of the Social Sciences 34(2):182-210. [MES]

Carballo, D. M., ed. 2013. Cooperation and collective action: archaeological perspectives. Boulder: University Press of Colorado. [MES]

Carballo, D. M., P. Roscoe, and G. M. Feinman. 2014. Cooperation and collective action in the cultural evolution of complex societies. Journal of Archaeological Method and Theory 21:98-133. [GMF]

Carneiro, R. 1970. A theory of the origin of the state. Science 169:733-738.

Carson, M. T. 2013. First settlement of remote Oceania: earliest sites in the Mariana Islands. Heidelberg: Springer.

Childe, V. G. 1942. What happened in history? Baltimore: Penguin. . 1958. Retrospective. Antiquity 32:69-74.

Chiu, S. 2007. Detailed analysis of Lapita face motifs: case studies from the Reef/Santa Cruz sites and New Caledonia Lapita site 13A. In Oceanic 
explorations: Lapita and western Pacific settlement. S. Bedford, C. Sand, and S. P. Connaughton, eds. Pp. 241-264. Canberra: Pandanus.

Clark, G. 2007. Standardization, specialization and Lapita ceramics. It Oceanic explorations: Lapita and western Pacific settlement. S. Bedford, C. Sand, and S. P. Connaughton, eds. Pp. 289-299. Canberra: Pandanus.

Cook, James. 1967. The voyage of the Resolution and Discovery, 1776-1780, vol. 3 of The journals of Captain James Cook on his voyages of discovery. J. C. Beaglehole, ed. Cambridge: Cambridge University Press. [LFF]

Cordy, R. 2003. Who made the feather cloaks in the Hawaiian Islands? some additional information. Journal of the Polynesian Society 112:157-161.

$\rightarrow$ D'Altroy, Terence N., and Timothy K. Earle. 1985. Staple finance, wealth finance, and storage in the Inka political economy. Current Anthropology $26: 187-206$

Deacon, A. B. 1934. Malekula: a vanishing people in the New Hebrides. London: Routledge.

$\rightarrow$ DeMarrais, E., L. J. Castillo, and T. Earle. 1996. Ideology, materialization and power strategies. Current Anthropology 37:15-31.

Dickinson, W., S. Bedford, and M. Spriggs. 2013. Petrography of temper sands in 112 reconstructed Lapita pottery vessels from Teouma (Efate) archaeological implications and relations to other Vanuatu tempers. Jour nal of Pacific Archaeology 4(2):1-20.

$\rightarrow$ Dow, G., and C. Reed. 2013. The origins of inequality: insider, outsider, elites, and commoners. Journal of Political Economy 121(3):609-641.

$\rightarrow$ Dye, T. S. 2010. Social transformation in Old Hawai'i: a bottom-up ap proach. American Antiquity 75:727-741.

$\rightarrow-2014$. Wealth in Old Hawai'i: good-year economics and the rise of pristine states. Archaeology in Oceania 49(2):59-85.

Eagleton, Terry. 2011. Why Marx was right. New Haven, CT: Yale University Press. [MES]

Earle, T. K. 1978. Economic and social organization of a complex chiefdom, the Halelea district, Kaua'i, Hawaii. Anthropological Papers 63. Ann Arbor: University of Michigan, Museum of Anthropology.

$\rightarrow-$ 1980. Prehistoric irrigation in the Hawaiian Islands: an evaluation of evolutionary significance. Archaeology and Physical Anthropology i Oceania 15:1-28.

1987. Specialization and the production of wealth: Hawaiian chiefdoms and the Inka empire. In Specialization, exchange and complex societies. E. Brumfiel and T. Earle, eds. Pp. 73-81. Cambridge: Cambridge University Press. Press.

. 2002. Bronze Age economics: the beginnings of political economies Boulder, CO: Westview.

. 2013. The 3M: materiality, materialism and materialization. In Counterpoint: essays in archaeology and heritage studies in honour of Professor Kristian Kristiansen. S. Bergerbrant and S. Sabatini, eds. Pp. 353360. BAR International Series 2508. Oxford: Oxbow.

Earle, T. K., and D. Doyel. 2008. The engineered landscapes of irrigation. In Economics and the transformation of landscape. L. Cliggett and C. A. Pool eds. Pp. 19-46. Lanham, MD: Altamira.

Ehrenreich, R., C. Crumley, and J. E. Levy. 1995. Heterarchy and the analysis of complex societies. Archaeological Paper 6. Washington, DC: American Anthropological Association.

Engels, F. 1883. Karl Marx's funeral. Der Sozialdemakrat, March 22.

.1972 (1884). The origin of the family, private property and the state. New York: Pathfinder.

Erickson, C. L. 1999. Neo-environmental determinism and agrarian "collapse" in Andean prehistory. Antiquity 73:634-642. [LFF]

. 2006. Intensification, political economy, and the farming community: in defense of a bottom-up perspective of the past. In Agricultural strategies. J. Marcus and C. Stanish, eds. Pp. 334-363. Los Angeles: Cotsen Institute of Archaeology, University of California, Los Angeles. [GMF]

Feinman, G. M. 2013. The dynamics of cooperation in context. In Cooperation and collective action: archaeological perspectives. D. M. Carballo, ed. Pp. 299-307. Boulder: University Press of Colorado. [GMF]

$\rightarrow$ Feinman, G. M., and C. P. Garraty. 2010. Preindustrial markets and marketing: archaeological perspectives. Annual Review of Anthropology 39:167191. [GMF]

$\rightarrow$ Feinman, G. M., and L. M. Nicholas. 2012. The late prehispanic economy o the Valley of Oaxaca: weaving threads from data, theory, and subsequent history. Research in Economic Anthropology 32:225-258. [GMF]

$\rightarrow$ Flannery, K. 1972. Cultural evolution of civilization. Annual Review of Ecol ogy and Systematics 3:399-426.
Flannery, K., and J. Marcus. 2012. The creation of inequality. Cambridge, MA: Harvard University Press.

Frank, A. G. 1993. Bronze Age world system cycles. Current Anthropology 34(4):383-429.

Fried, M. 1967. The evolution of political society: an essay in political economy. New York: Random House.

Friedman, J. 1974. Marxism, structuralism and vulgar materialism. Man, n.s., 9(3):444-469.

. 1981. Notes on structure and history in Oceania. Folk 23:275295

1982. Catastrophe and continuity in social evolution. In Theory and explanation in archaeology. C. Renfrew, M. J. Rowlands, and B. A. Segraves, eds. Pp. 175-196. London: Academic Press.

Friedman, J., and M. Rowlands, eds. 1978. Notes towards an epigenetic model of the evolution of "civilization." In The evolution of social systems. Pp. 201-276. London: Duckworth.

Friedman, K. E., and J. Friedman. 2008. Historical transformations: the anthropology of global systems. Lanham, MD: Altamira.

Gailey, Christine W. 1987. Kinship to kingship: gender hierarchy and state formation in the Tongan Islands. Austin: University of Texas Press. [LFF] Garanger, J. 1972. Archéologie des Nouvelles-Hébrides: contribution à la Connaissance des Iles du Centre. Publications de la Société des Océanistes 30. Paris: ORSTOM.

Gilman, A. 1981. The development of social stratification in Bronze Age Europe. Current Anthropology 22:1-24.

1989. Marxism in American archaeology. In Archaeological thought in America. C. C. Lamberg-Karlovsky, ed. Pp. 63-73. Cambridge: Cambridge University Press.

1995. Prehistoric European chiefdoms: rethinking "Germanic" societies. In Foundations of social inequality. D. Price and G. Feinman, eds. Pp. 235-251. New York: Plenum.

Goldman, I. 1970. Ancient Polynesian society. Chicago: University of Chicago Press.

Gosden, C., and C. Pavlides. 1994. Are islands insular? landscape versus seascape in the case of the Arawe Islands, Papua New Guinea. Archaeology in Oceania 29:162-171.

Graeber, D. 2001. Towards an anthropological theory of value: the false coin of our own dreams. New York: Palgrave Macmillan. [TT]

Green, R. C. 1979. Early Lapita art from Polynesia and Island Melanesia: continuities in ceramic, barkcloth and tattoo decorations. In Exploring the visual art of Oceania. S. Mead, ed. Pp 13-31. Honolulu: University of Hawai'i Press.

1992. Definitions of the Lapita cultural complex and its non-ceramic component. In Poterie Lapita et Peuplement. Jean-Christophe Galipaud, ed. Pp. 7-20. Noumea: ORSTOM. [JS]

1994. Archaeological problems with the use of linguistic evidence in the reconstruction of rank, status and social organisation in ancestral Polynesian society. In Austronesian terminologies: continuity and change. A. Pawley and M. Ross, eds. Pp. 171-184. Pacific Linguistics C-127. Canberra: Department of Linguistics, Research School for Pacific Studies, Australian National University.

- 2002. Rediscovering the social aspects of ancestral Oceanic societies through archaeology, linguistics and ethnology. In Fifty years in the field: essays in honour and celebration of Richard Shutler Jr's archaeological career. S. Bedford, C. Sand, and D. Burley, eds. Pp. 21-35. NZAA Monograph 25. Auckland: New Zealand Archaeological Association.

Green, R. C., and Patrick V. Kirch. 1997. Lapita exchange systems and their Polynesian transformations: seeking explanatory models. In Prehistoric long-distance interaction in Oceania: an interdisciplinary approach. Marshal I. Weisler, ed. Pp. 19-37. Auckland: New Zealand Archaeological Association. [JS]

Handy, E. S. C. 1940. His plants, methods and areas of cultivation, vol. 1 of The Hawaiian planter. Bishop Museum Bulletin 161. Honolulu: Bishop Museum.

Harding, Thomas G. 1994. Precolonial New Guinea trade. Ethnology 33(2): 101-125. [JS]

Harrison, S. 1993. The mask of war: violence, ritual and the self in Melanesia. Manchester: Manchester University Press. [TT]

Hayden, B. 1983. Social characteristics of early Austronesian colonizers. Bulletin of the Indo-Pacific Prehistory Association 4:123-134.

. 2001. Richman, poorman, beggarman, chief: the dynamics of social inequality. In Archaeology at the millennium. G. M. Feinman and T. D. Price, eds. Pp. 231-272. New York: Springer. [PS] 
Hayden, B., and S. Villeneuve. 2013. The power of secret societies in the past Paper presented at the 78th Annual Meeting of the Society for American Archaeology, Honolulu.

$\rightarrow$ Hegmon, M. 2003. Setting the theoretical egos aside: issues and theory in North American archaeology. American Antiquity 68(2):213-243.

Hobsbawm, E., ed. 1965. Introduction. In Karl Marx: pre-capitalist economic formations. Pp. 9-65. New York: International.

Hodder, Ian. 1982. Symbolic and structural archaeology. Cambridge: Cambridge University Press.

2012. Entangled: an archaeology of the relationships between human and things. Malden, MA: Wiley-Blackwell.

Hommon, R. 2013. The Ancient Hawaiian state: origins of a political society. New York: Oxford University Press.

$\rightarrow$ Horrocks, M., and S. Bedford. 2005. Microfossils of introduced Araceae (aroids) reveal Lapita horticulture in Vanuatu. Archaeology in Oceania 39:67-74.

$\rightarrow$. 2010. Introduced Dioscorea spp. starch in Lapita and later deposits, Vao Island, Vanuatu. New Zealand Journal of Botany 48(3):179-183.

$\rightarrow$ Horrocks, M., S. Bedford, and M. Spriggs. 2009. A short note on banana (Musa) phytoliths in Lapita, immediately post-Lapita and modern period archaeological deposits from Vanuatu. Journal of Archaeological Science 36:2048-2054.

Irwin, Geoffrey. 1992. The prehistoric exploration and colonisation of the Pacific. Cambridge: Cambridge University Press.

2004. Kohika: the archaeology of a late Maori lake village in the Ngati Awa Rohe Bay of Plenty, New Zealand. Auckland: Auckland University Press. [JS]

$\rightarrow$ Keesing, R. M. 1984. Rethinking mana. Journal of Anthropological Research 40:137-156. [PS]

$\rightarrow$ Kirch, P. V. 1976. Ethnoarchaeological investigations in Futuna and Uvea (western Polynesia). Journal of the Polynesian Society 85:27-69.

. 1984. The evolution of the Polynesian chiefdoms. Cambridge: Cambridge University Press.

1985. Feathered gods and fishhooks: an introduction to Hawaiian archaeology and prehistory. Honolulu: University of Hawai'i Press. [PVK]

$\rightarrow \longrightarrow$. 1988a. Circumscription and sociopolitical evolution in Polynesia American Behavioral Scientist 31:117-133.

$\rightarrow \longrightarrow$. 1988b. Long-distance exchange and island colonisation: the Lapita case. Norwegian Archaeological Review 21(2):103-117.

$\rightarrow \quad$ 1991. Prehistoric exchange in western Melanesia. Annual Review of Anthropology 20:142-165.

. 1997. The Lapita peoples: ancestors of the Oceanic world. Oxford: Blackwell.

. 2000. On the roads of the winds. Berkeley: University of California Press.

2010. How chiefs became kings: divine kingship and the rise of archaic states in ancient Hawai' $i$. Berkeley: University of California Press.

. 2012. A shark going inland is my chief. Berkeley: University of Cal ifornia Press.

Kirch, P. V., and R. C. Green. 2001. Hawaiki, ancestral Polynesia: an essay in historical anthropology. Cambridge: Cambridge University Press. [TT]

$\rightarrow$ Kirch, P. V., P. Mills, S. Lundblad, J. Sinton, and J. Kahn. 2012. Interpolity exchange of basalt tools facilitated via elite control in Hawaiian archaic states. Proceedings of the National Academy of Sciences of the United States of America 109(4):145-160.

Kirch, P. V., and M. Sahlins. 1992. Anahulu: the anthropology of history in the Kingdom of Hawai i $i$. Chicago: University of Chicago Press. [PVK]

$\rightarrow$ Kiser, Edgar, and Denielle Kane. 2007. The perils of privatization: how the characteristics of principals affected tax farming in the Roman Republic and Empire. Social Science History 31:191-212. [MES]

Kolb, Michael. 1994. Monumental grandeur and the rise of religious authority in precontact Hawaii. Current Anthropology 34(1):1-38.

$\rightarrow$ Kononenko, N. 2012. Middle and late Holocene skin-working tools in Melanesia: tattooing and scarification? Archaeology in Oceania 47(1):14-28.

Kristiansen, K. 2007. The rules of the game: decentralised complexity and power structures. In Socialising complexity. S. Kohring and S. WynneJones, eds. Pp. 60-76. Oxford: Oxbow.

. 2014. Towards a new paradigm? the third science revolution and its possible consequences in archaeology. Current Swedish Archaeology 22:11-34. [GMF]

$\rightarrow$ Ladefoged, T., and M. W. Graves. 2008. Variable development of dryland agriculture in Hawai i: a finegrained chronology from the Kohala field system. Current Anthropology 49:771-802.
Ladefoged, T., P. Kirch, S. Gon, O. Chadwick, A. Hartshorn, and P. Vitousek. 2009. Opportunities and constraints for intensive agriculture in the $\mathrm{Ha}$ waiian archipelago prior to European contact. Journal of Archaeological Sciences 36:2374-2383.

Lansing, J. Stephen. 1987. Balinese "water temples" and the management of irrigation. American Anthropologist 89(2):326-341. [LFF]

. 2009. Priests and programmers: technologies of power in the engineered landscape of Bali. Princeton, NJ: Princeton University Press. [LFF]

Lansing, J. Stephen, and James N. Kremer. 1993. Emergent properties of Balinese water temple networks: coadaptation on a rugged fitness landscape. American Anthropologist 95(1):97-114. [LFF]

Lass, B. 1998. Crafts, chiefs, and commoners: production and control in precontact Hawaii. In Craft and social identity. C. Costin and R. Wright, eds. Pp. 19-30. Archaeological Papers 8. Arlington, VA: American Anthropological Association.

Layard, J. W. 1942. Stone men of Malekula: the small island of Vao. London: Chatto \& Windus.

Leach, Edmund R. 1954. Political systems of highland Burma: a study of Kachin social structure. Boston: Beacon. [LFF]

Levi, Margaret. 1988. Of rule and revenue. Berkeley: University of California Press. [GMF, MES]

Liu, Li. 2004. The Chinese Neolithic. New York: Cambridge University Press. [LFF]

Luders, D. 2001. Retoka revisited and Roimata revised. Journal of the Polynesian Society 110(3):247-287. [TT]

Malinowski, B. 1922. Argonauts of the western Pacific. London: Routledge.

Malo, David. 1951. Hawaiian antiquities. Bernice P. Bishop Museum Special Publication 2. Honolulu: Bishop Museum Press. [PVK]

Mann, M. 1986. The sources of social power. Cambridge: Cambridge University Press.

Marx, K. 1967 (1867). The process of capitalist production, vol. 1 of Capital: a critique of political economy. New York: International.

Marx, K., and F. Engels. 2012 (1848). The communist manifesto. New Haven, CT: Yale University Press.

McCoy, M. D., and M. W. Graves. 2010. What shaped agricultural innovation in Hawaii? a case study in the history of innovative agricultural practices on Hawai'i Island. World Archaeology 42:90-107.

McElroy, W. 2012. Approaches to dating wetland agricultural features: an example from Wailua Valley, Moloka'i Island, Hawai'i. In Irrigated taro (Colocasia esculenta) in the Indo-Pacific: biological, social and historical perspectives. M. Spriggs, D. Addison, and P. J. Matthews, eds. Pp. 135-154. Senri Ethnological Studies 78. Osaka: National Museum of Ethnology.

McGuire, Randall H. 2008a. Archaeology as political action. Berkeley: University of California Press. [MES]

. 2008b. Marxism. In Handbook of archaeological theory. R. Bentley, H. Maschner, and C. Chippindale, eds. Pp. 73-93. Lanham, MD: Altamira.

McGuire, R., M. O'Donovan, and L. Wurst. 2005. Probing praxis in archaeology: the last eighty years. Rethinking Marxism 17:355-372.

McIntosh, S. 1999. Beyond chiefdoms: pathways to complexity in Africa. Cambridge: Cambridge University Press.

Monson, Andrew, and Walter Scheidel, eds. 2015. Fiscal regimes and the political economy of premodern states. New York: Oxford University Press. [MES]

$\rightarrow$ Morgan, Charles G. 1973. Archaeology and explanation. World Archaeology 4(3):259-276. [MES]

Morgan, L. H. 1877. Ancient society. New York: Henry Holt.

. 1901. League of the Ho-de-no-sau-nee or Iroquois. New York: Dodd, Mead \& Co. [LFF]

$\rightarrow$ Neitzel, Jill, and T. Earle. 2014. Dual-tier approach to societal evolution and types. Journal of Anthropological Archaeology 36:181-195.

Netting, R. McC. 1993. Smallholders, householders: farm families and the ecology of intensive sustainable agriculture. Stanford, CA: Stanford University Press. [GMF]

Oliver, D. L. 1955. A Solomon Island society. Cambridge, MA: Harvard University Press. [PS]

. 1956. Comparative political systems: a case study. Bulletin of the Philadelphia Anthropological Society 10(1). [PS]

. 1971. Southern Bougainville. In Politics in New Guinea. R. Berndt, M. Lawrence, and P. Lawrence, eds. Pp. 276-297. Nedlands: University of Western Australia Press. [PS]

Olson, M. 1965. The logic of collective action. Cambridge, MA: Harvard University Press. [GMF] 
Osmond, M. 1998. Horticultural practices. In Material culture, vol. 1 of The lexicon of Proto Oceanic: the culture and environment of ancestral Oceanic society. Malcolm Ross, Andrew Pawley, and Meredith Osmond, eds. Pp. 115-142. Pacific Linguistics C-152. Canberra: Department of Lin guistics, Research School for Pacific and Asian Studies, Australian National University.

Ostrom, Elinor. 1990. Governing the commons: the evolution of institution for collective action. New York: Cambridge University Press. [LFF]

- 1992. Crafting institutions for self-governing irrigation systems. San Francisco: Institute for Contemporary Studies. [GMF]

Pawley, Andrew. 1981. Melanesian diversity and Polynesian homogeneity: a unified explanation for language. In Studies in Pacific languages and cultures in honour of Bruce Biggs. J. Hollyman and A. Pawley, eds. Pp. 269-309. Auckland: Linguistic Society of New Zealand.

. 2003. Locating Proto Oceanic. In The physical environment, vol. 2 of The lexicon of Proto Oceanic: the culture and environment of ancestral Oceanic society. Malcolm Ross, Andrew Pawley, and Meredith Osmond, eds. Pp. 17-34. Pacific Linguistics 545. Canberra: Department of Linguistics, Research School for Pacific and Asian Studies, Australian National University. [JS]

$\rightarrow$ Peregrine, P. N. 2001. Matrilocality, corporate strategy, and the organization of production in the Chacoan world. American Antiquity 66(1):36-46 [LFF]

Radcliffe-Brown, A. R. 1952. Structure and function in primitive societies. London: Oxford University Press.

Ricardo, D. 1817 (1811). The principles of political economy and taxation. New York: Dutton

Robin, C. 2013. Everyday life matters. Gainesville: University Press of Florida

$\rightarrow$ Roscoe, Paul. 2000. New Guinea leadership as ethnographic analogy: a critical review. Journal of Archaeological Method and Theory 7(2):79-126. [JS]

Roseberry, W. 1989. Anthropologies and histories: essays in culture, history and political economy. New Brunswick, NJ: Rutgers University Press.

Sahlins, M. 1958. Social stratification in Polynesia. Seattle: University of Washington Press.

1985. Islands of history. Chicago: University of Chicago Press.

1990. The political economy of grandeur in Hawaii from 1810 to

1830. In Culture through time. E. Ohnuki-Tierney, ed. Pp. 26-56. Stanford, CA: Stanford University Press. [PVK]

1999. From totemic differences to political society in Polynesia: the Hawaiians invent "The People." Paper presented at the Valerio Valer Memorial Symposium, University of Chicago. [PVK]

$\rightarrow$ Saitta, Dean. 1997. Power, labor, and the dynamics of change in Chacoan political economy. American Antiquity 62:7-26.

$\rightarrow$. 2005. Marxism, tribal society and the dual nature of archaeology. Rethinking Marxism 17:385-397.

Sayer, D. 1987. The violence of abstraction. Oxford: Blackwell.

Schelling, T. C. 2006. Micromotives and macrobehavior. New York: Norton. [GMF]

Service, E. 1962. Primitive social organization: an evolutionary perspective. New York: Random House.

Sheppard, P. J. 1992. A report on the flaked lithic assemblages from three southeast Solomons Lapita sites (SE-SZ-8, SE-RF-2 and SE-RF-6). In Poterie Lapita et Peuplement: Actes du Colloque Lapita, Noumea, NouvelleCaledonie, Janvier 1992. J. C. Galipaud, ed. Pp. 135-153. Noumea: ORSTOM.

$\rightarrow$. 1993. Lapita lithics: trade/exchange and technology: a view from the Reefs/Santa Cruz. Archaeology in Oceania 28(3):121-137. [JS]

$\rightarrow$ 2011. Lapita colonization across the near/remote Oceania boundary. Current Anthropology 52:799-840. [PS]

Sheppard, P. J., and R. T. Walter. 2013. Diversity and networked interdependence in the western Solomons. In Pacific archaeology: documenting the past 50,000 years, papers from the 2011 Lapita Pacific Archaeology Conference. G. R. Summarhayes and B. Hallie, eds. Pp. 138-147. Dunedin, New Zealand: University of Otago, Department of Anthropology and Archaeology. [PS]

Sheppard, P. J., R. Walter, and T. Nagaoka. 2000. The archaeology of headhunting in Roviana Lagoon, New Georgia. Journal of the Polynesian So ciety 109:4-38. [TT]

Smith, A. 1778. The wealth of nations. London: Strahan.

Smith, M. E. 1996. The Aztecs. Malden, MA: Blackwell. [GMF]

$\rightarrow-2004$. The archaeology of ancient state economies. Annual Review of Anthropology 33:73-102.
2011. Why anthropology is too narrow an intellectual context for archaeology. Anthropologies. http://www.anthropologiesproject.org/2011 /05/why-anthropology-is-too-narrow.html. [MES]

2012. State formation in Hawaii: review of How chiefs became kings, by Patrick V. Kirch. Cliodynamics 3(2):333-343. http://escholarship.org /uc/item/9n8560x3. [MES]

Smith, M. E., G. Feinman, R. Drennan, T. Earle, and I. Morris. 2012. Archaeology as a social science. Proceedings of the National Academy of Sciences of the United States of America 109:7617-7621.

$\rightarrow$ Specht, Jim. 1981. Obsidian sources at Talasea, West New Britain, Papua New Guinea. Journal of the Polynesian Society 90(3):337-356. [JS] 2002. Obsidian, colonising and exchange. In Fifty years in the field: essays in honour and celebration of Richard Shutler Jr's archaeological career. Stuart Bedford, Christophe Sand, and David Burley, eds. Pp. 37-49. NZAA Monograph 25. Auckland: New Zealand Archaeological Association. [JS]

Spielmann, K. 1998. Ritual craft specialization in middle range societies. In Craft and social identity. C. Costin and R. Wright, eds. Pp. 153-159. Archaeological Papers 8. Arlington, VA: American Anthropological Association.

Spriggs, M. 1984. Marxist perspectives in archaeology. Cambridge: Cambridge University Press.

1985. Prehistoric humanly-induced landscape enhancement in the Pacific: examples and implications. In Prehistoric intensive agriculture in the tropics. I. Farrington, ed. Pp. 409-434. BAR International Series 232. Oxford: British Archaeological Reports.

. 1986. Landscape, land use and political transformation in southern Melanesia. In Island societies: archaeological approaches to evolution and transformation. P. Kirch, ed. Pp. 6-19. Cambridge: Cambridge University Press.

1997a. The Island Melanesians. Oxford: Blackwell.

- 1997b. Landscape catastrophe and landscape enhancement: are either or both true in the Pacific? In Historical ecology in the Pacific Islands: prehistoric environmental and landscape change. P. Kirch and T. Hunt, eds. Pp. 80-104. New Haven, CT: Yale University Press.

- 1997c. Who taught Marx, Engels and Morgan about Australian Aborigines? History and Anthropology 10(2):185-218.

. 2010. Geomorphic and archaeological consequences of human arrival and agricultural expansion on Pacific islands: a reconsideration after 30 years of debate. In Altered ecologies: fire, climate and human influence on terrestrial landscapes. S. Haberle, J. Stevenson, and M. Prebble, eds. Pp. 239-252. Terra Australis 32. Canberra: Department of Archaeology and Natural History, Research School for Pacific and Asian Studies, Australian National University.

. 2013. Leaving safe harbours: movement to immobility, homogeneity to diversification: a comparative archaeological sequence from the western Pacific. In Counterpoint: essays in archaeology and heritage studies in honour of Professor Kristian Kristiansen. S. Bergerbrant and S. Sabatini, eds. Pp. 549-556. BAR International Series 2508. Oxford: Oxbow.

Spriggs, M., and S. Bedford. 2013. Is there an incised Lapita phase after dentate-stamped pottery ends? data from Teouma, Efate Island, Vanuatu. In Pacific archaeology: documenting the past 50,000 years. G. R. Summerhayes and H. Buckley, eds. Pp. 148-156. University of Otago Studies in Archaeology 25. Dunedin, New Zealand: Department of Anthropology and Archaeology, University of Otago.

Stein, Gil. 1994. Economy, ritual, and power in 'Ubaid Mesopotamia. In Chiefdoms and early states in the Near East: the organizational dynamics of complexity. G. Stein and M. S. Rothman, eds. Pp. 35-46. Madison, WI: Prehistory. [LFF]

Steward, J. 1955. Theory of culture change. Urbana: University of Illinois Press.

Stiles, T. 2009. The first tycoon: epic life of Cornelius Vanderbilt. New York: Knopf.

Strathern, Marilyn. 1988. The gender of the gift. Berkeley: University of California Press. [TT]

$\rightarrow$. 1996. Cutting the network. Journal of the Royal Anthropological Institute 2(3):517-535. [TT]

$\rightarrow$ Summerhayes, Glenn R. 1998. The face of Lapita. Archaeology in Oceania $33: 100$.

$\rightarrow \quad$ 2000. Far western, western and eastern Lapita: a re-evaluation. Asian Perspectives 39:109-138.

. 2001. Lapita interaction. Terra Australis 15. Canberra: Department of Archaeology and Natural History, Australian National University. 
Summerhayes, Glenn R., J. Roger Bird, Richard Fullagar, Chris Gosden, Jim Specht, and Robin Torrence. 1998. Application of PIXE-PIGME to archaeological analysis of changing patterns of obsidian use in West New Britain, Papua New Guinea. In Archaeological obsidian studies: metho and theory. M. Steven Shackley, ed. Pp. 129-158. New York: Plenum. [JS]

Swadling, P. 1996. Plumes from paradise: trade cycles in outer Southeast Asia and their impact on New Guinea and nearby islands until 1920. Boroko: Papua New Guinea National Museum.

Swanton, John R. 1928. Social organization and social usages of the Indians of the Creek Confederacy. Washington, DC: US Government Printing Office. [LFF]

Swenson, Edward. 2014. The materialities of place making in the ancient Andes: a critical appraisal of the ontological turn in archaeological interpretation. Journal of Archaeological Method and Theory. doi:10.1007 /s10816-014-9202-2. [MES]

Szabo, K. 2010a. Lapita shell-working and shell artefacts. In Lapita: ancetres oceaniens [Lapita: oceanic ancestors]. C. Sand and S. Bedford, eds. Pp. 226239. Paris: Musee de Quai Branly/Somogy.

2010b. Shell artefacts and shell-working within the Lapita cultural complex. Journal of Pacific Archaeology 1:115-127.

Thomas, J. 2001. Understanding the Neolithic. London: Routledge.

Thomas, T. 2009. Communities of practice in the archaeology of Nev Georgia, Rendova and Tetepare. In Lapita: ancestors and descendants. P. J. Sheppard, T. Thomas, and G. Summerhayes, eds. Pp. 119-145. NZAA Monograph 28. Auckland: New Zealand Archaeological Association. [TT]

Thurnwald, R. C. 1934. Pigs and currency in Buin. Oceania 5:125-141. [PS]

Thurston, Tina L. 2010. Bitter arrows and generous gifts: what was a "king" in the European Iron Age? In Pathways to power. T. D. Price and G. M. Feinman, eds. Pp. 193-254. New York: Springer. [LFF]

Tilly, Charles. 2008. Explaining social processes. Boulder, CO: Paradigm. [MES]

$\rightarrow$ Torrence, Robin, Sarah Kelloway, and Peter White. 2013. Stemmed tools social interaction, and voyaging in early-mid Holocene Papua New Guinea. Journal of Island and Coastal Archaeology 8:287-310. [JS]

$\rightarrow$ Torrence, Robin, and Pamela Swadling. 2008. Social networks and the spread of Lapita. Antiquity 82(317):600-616. [JS]
Torrence, Robin, Peter White, and Nina Kononenko. 2013. Obsidian stemmed tools from Barema, New Britain, Papua New Guinea. Australian Archaeology 77:1-8. [JS]

Trawick, Paul B. 2001. Successfully governing the commons: principles of social organization in an Andean irrigation system. Human Ecology 29 (1):1-25. [LFF]

Trigger, B. 1980. Gordon Childe: revolutions in archaeology. London: Thames \& Hudson.

1998. Sociocultural evolution. London: Wiley-Blackwell.

2003. Understanding early civilizations: a comparative study. New York: Cambridge University Press.

2006. A history of archaeological thought. 2nd edition. New York: Cambridge University Press. [MES]

Twitchett, Denis. 1979. Sui and Tang China, 589-906, part 1, vol. 3 of The Cambridge history of China. Cambridge: Cambridge University Press. [LFF]

Valentin, F., M. Spriggs, S. Bedford, and H. Buckley. 2011. Vanuatu mortuary practices over three millennia: Lapita to the early contact period. Journal of Pacific Archaeology 2(2):49-65.

Wallerstein, I. 1974. The modern world-system: capitalist agriculture and the origins of the European world-economy in the sixteenth century. New York: Academic Press.

White, A., T. Worthy, S. Hawkins, S. Bedford, and M. Spriggs. 2010. Megafaunal meiolaniid horned turtles survived until early human settlement in Vanuatu, Southwest Pacific. Proceedings of the National Academy of Sciences of the United States of America 107:15512-15516.

White, L. 1958. The evolution of culture. New York: McGraw-Hill.

Wilken, G. C. 1987. Good farmers: traditional agricultural resource management in Mexico and Central America. Berkeley: University of California Press. [GMF]

Willey, G., and J. Sabloff. 1974. A history of American archaeology. San Francisco: Freeman.

Winters, Jeffrey. 2011. Oligarchy. Cambridge: Cambridge University Press. Wurst, LouAnn, and Stephen A. Mrozowski. 2014. Toward an archaeology of the future. International Journal of Historical Archaeology 18(2):210223. [MES]

Younger, S. M. 2012. Calculating chiefs: simulating leadership, violence, and warfare in Oceania. Saarbrücken, Germany: Lambert Academic. 